Department of Economics- FEA/USP

\title{
The impact of wind power on the Brazilian labor market
}

SOLANGE GONÇALVES

THIAgo RODRIGUES

André Chagas

WorkING PAPER SERIES № 2019-41 


\title{
DEPARTMENT OF ECONOMICS, FEA-USP \\ WORKING PAPER № 2019-41
}

\section{The impact of wind power on the Brazilian labor market*}

\author{
Solange Gonçalves (slgoncalves@unifesp.br) ${ }^{1}$ \\ Thiago Rodrigues (rodrigues.t@gmail.com)² \\ André Chagas (achagas@usp.br) ${ }^{3}$
}

\begin{abstract}
:
Wind power is an important source of renewable energy. Beyond the environmental dimension, the wind energy may contribute to the local development. Due to its weather conditions, Brazil emerges as one of the leading countries in the generation of wind power. This study estimates the impact of wind farms on the Brazilian labor market, through the exploration of the staggered nature of the sequential process of wind farm implantation between 2004 and 2016. We estimate the treatment effect parameters using a Difference--in--Differences (DiD) approach with: i) multiple time periods, ii) variation in treatment timing, and iii) dynamic treatment effects, through an event study design. We aggregate information from several data sources into a panel and we analyze the impact on employment and wages, by considering economic sectors, educational levels, and firm sizes. Our findings suggest that wind farms increase employment in the industry, agriculture and construction, and increase the wages in all economic sectors. Additionally, we find positive effects on the employment and wages of less--educated workers, and of small and medium--sized firms. The impact of this intervention can last for up to two years. Our results suggest that wind power may generate significant social impacts through the labor market, by contributing to local development and increasing social welfare in developing economies.
\end{abstract}

Keywords: Wind power, staggered difference-in-differences, event study, employment, wages, labor market

JEL Codes: Q42, C23, R58

\footnotetext{
* The views and opinions expressed in this study are those of the authors and do not necessarily reflect the position of EPE.

${ }^{1}$ Professor, Federal University of São Paulo (UNIFESP)

${ }^{2}$ Energy Research Analyst, Energy Research Office (EPE)

${ }^{3}$ Professor, University of São Paulo (USP)
} 


\title{
The impact of wind power on the Brazilian labor market*
}

\author{
Solange Gonçalves ${ }^{\dagger} \quad$ Thiago P. Rodrigues ${ }^{\ddagger} \quad$ Andre S. Chagas ${ }^{\S}$
}

\begin{abstract}
Wind power is an important source of renewable energy. Beyond the environmental dimension, the wind energy may contribute to the local development. Due to its weather conditions, Brazil emerges as one of the leading countries in the generation of wind power. This study estimates the impact of wind farms on the Brazilian labor market, through the exploration of the staggered nature of the sequential process of wind farm implantation between 2004 and 2016. We estimate the treatment effect parameters using a Difference-inDifferences (DiD) approach with: i) multiple time periods, ii) variation in treatment timing, and iii) dynamic treatment effects, through an event study design. We aggregate information from several data sources into a panel and we analyze the impact on employment and wages, by considering economic sectors, educational levels, and firm sizes. Our findings suggest that wind farms increase employment in the industry, agriculture and construction, and increase the wages in all economic sectors. Additionally, we find positive effects on the employment and wages of less-educated workers, and of small and medium-sized firms. The impact of this intervention can last for up to two years. Our results suggest that wind power may generate significant social impacts through the labor market, by contributing to local development and increasing social welfare in developing economies.
\end{abstract}

Keywords: Wind power, staggered difference-in-differences, event study, employment, wages, labor market.

JEL Codes: Q42, C23, R58

${ }^{*}$ The views and opinions expressed in this study are those of the authors and do not necessarily reflect the position of EPE.

${ }^{\dagger}$ Federal University of Sao Paulo (UNIFESP). Email: slgoncalves@unifesp.br

${ }^{\ddagger}$ Energy Research Office (EPE). Email: rodrigues.t@gmail.com

${ }^{\S}$ University of Sao Paulo (USP). Email: achagas@usp.br 


\section{Introduction}

Debates on the importance of renewable energy arise in the context of climate change. In December 2015, during the 21st United Nations Climate Change Conference (COP21), governments from around 190 countries presented their strategies for the reduction of national greenhouse gas emissions.

In this context, wind power is an important source of renewable energy. Although it is not widely adopted worldwide, wind energy could satisfy $20 \%$ of the world's demand for electricity by 2050 [17]. Wind power generation has grown exponentially worldwide since the late 1990s, especially in the European Union and in the United States. This renewable energy source is notable for its lower production costs, supply security, and environmental sustainability [20]. In addition, there are some specific technical advantages, such as: i) no water is utilized and no greenhouse gases are emitted during operation; ii) there is no danger of fuel leakage; iii) the simultaneous occupation of soil, by crop or pasture, is possible in the perimeter of the wind farm; (iv) wind turbines occupy a relatively small area.; and v) it allows geographically isolated and off-grid regions to generate energy without incurring high costs with transmission networks [13].

In addition to the environmental impacts, wind energy is relevant in the context of contributing to local development. According to the International Renewable Energy Agency (IRENA), the wind power industry has employed approximately 1,15 million people worldwide in 2017, inclusive of the onshore and offshore segments [24]. Rio and Burguillo [16] assert that the implementation of renewable energy projects can contribute to local development, especially in the rural areas. These authors assert that during the construction of a wind farm, the demand for goods and services increases, and local suppliers can benefit from a higher income and temporary employment. Additionally, changes in the structure of communities may occur, such as improvements in public infrastructure, lower-cost energy supply, and so on. Blanco and Rodrigues [8] find that wind energy in some countries in the European Union, creates a significant number of direct jobs, mainly in the wind turbines and components industry that tend to be supplied by local companies.

This study aims to estimate the effects of wind farms on the levels of employment and wages in an economy. We investigate this aspect while focusing on the following questions: i) Does the wind farm implementation indeed contribute to local development through increases of employment and wages? ii) Is the impact of the wind power concentrated into specific economic sectors? iii) Additionally, is the increase in employment and wages concentrated among the lessskilled and disadvantaged workers? iv) What are the phases in which significant impacts can be expected and for how long time?

We choose to address these aspects to the greatest possible extent with the data for Brazil, and hence, provide evidence on the potential role of wind power in contributing to local development in a developing country. We explore the staggered nature of the sequential process of wind farm implementation in the country. We consider the fact that the installation of wind farms occurs 
at a particular point in time, such that cities henceforth, remain exposed to this treatment for a sustained period of time. Thus, we consider the identification and estimation of treatment effect parameters using a Difference-in-Differences (DiD) approach with: i) multiple time periods, ii) variation in treatment timing, and iii) dynamic treatment effects of wind farm implementation, in an event study design. We aggregate information from several data sources to construct a longitudinal database for municipalities from 2004 to 2016. We analyze the impact of wind energy on employment and wages of workers, by economic sectors, by worker educational levels and by firm sizes.

During the COP21, Brazil committed to reducing emissions by $37 \%$ in 2025 and $43 \%$ in 2030 [18. In 2018, according to the Global Wind Energy Council (GWEC), this developing country ranked eighth in global installed capacity and fifth in the ranking of new onshore installed capacity. Brazil ended 2018 with 14,71 GW of installed wind energy, thereby indicating an annual growth of $15.18 \%$ [21]. The conducive wind conditions in Brazil, characterized by high speed and regularity, has been the primary determinant of the growth of wind energy projects in recent years. The northeastern region of the country accounts for $80 \%$ of the generated wind energy. In addition, IRENA suggests that in Brazil approximately 33,700 people are engaged in the manufacturing of wind turbine components, in tower construction and in the installation, operation, and maintenance of wind farms [24].

In this study, our findings suggest that wind energy not only increases employment in the industry, agriculture and construction, but also increases wages across all sectors in the economy, including commerce and services. Indeed, it is possible to observe positive and statistically significant effects of wind energy on the employment and wage levels of workers with elementary and high school educational levels, and of small and medium-sized firms. This evidences that the expansion of wind farm projects could have relevant social impacts through labor market outcomes for less-skilled workers, thereby contributing to local development geared towards increasing welfare and reducing social inequalities.

In the second application of the staggered DiD approach, in which we consider the dynamic treatment effects of wind energy, through an event study, we find positive and statistically significant impacts of wind power on employment at the exact moment of intervention and during the two periods prior to wind farm implementation. However, we verify through heterogeneity analysis and simulations that this anticipatory effect is related to the construction phase of wind farms, whose start dates are unavailable in our database. Regarding wage levels, we find contemporaneous impacts and effects for the two post-intervention periods. The construction, commerce and services, and agricultural sectors are the main drivers of such contemporaneous effects. The impact in the two post-intervention periods can be explained by the indirect effects of implementing wind farm projects spreading throughout the local economy. The contemporaneous effect of implementing wind power projects on employment and on wages is $5.3 \%$ and $8.0 \%$, respectively. 
Our study contributes to the scarce literature on the socioeconomic effects of wind power energy, a renewable energy source in the context of a developing country characterized by favorable wind speed and occurrence conditions. Wei et al. [30] and Simas and Pacca [29], found that in Brazil, wind farm projects create the most jobs during the construction and installation stages. Rintzel et al. 28] and Martini et al. [26] also verify the positive impact of wind farm projects on the Brazilian labor market and GDP. Notwithstanding these studies that present evidence regarding the relation between wind energy and local development, these are not based on methodological approaches that allow for isolating the effects of wind farm implementation. Our contribution is innovative, since we explore the exogenous nature of the location of wind farms across Brazil, based on speed and occurrence of winds, and we consider the identification and estimation of treatment effect parameters through two recently developed extensions of the Difference-in-Differences (DiD) approach.

This article comprises of four sections, apart from the introduction, bibliographical references and appendices. The second section provides a brief overview of wind energy in Brazil. The third section presents the empirical methodology and a description of the data. Finally, the fourth section presents the empirical results and the fifth section, the concluding remarks and discussion.

\section{Wind power in Brazil}

Brazil's first wind farm was established on Fernando de Noronha, a small archipelago located in the northeast region, in 1992. However, the exploration of the commercial potential of wind power in the Brazilian context, began only in 2002, with the launching of the Program for Incentive to Alternative Energy Sources (PROINFA) ${ }^{1}$. The program aimed to increase the share of renewable energy sources, such as wind energy, small hydroelectric plants, and biomass, in the National Interconnected System (SIN) ${ }^{2}$, through the provision of governmental incentives to independent producers. The first PROINFA's phase would take place between 2006 and 2008, and the government would acquire the wind power that is being generated for a period of twenty years. However, under this program, just 54 wind farms were implemented, with a potential of $1.40 \mathrm{GW}$.

Prior to the launching of PROINFA, Law 10,848 established energy contracts through auctions in 2004. The first energy auction where wind power competed with other energy sources, including non-renewable energy sources, occurred only in 2008. Following this, there was a significant surge in the number of registered wind power projects. Wind power projects accounted for less than $10 \%$ of the registered projects in 2007 . This share increased to $54 \%$ in 2018 . Thus, there was a growth in the number of wind farms across Brazilian municipalities, as shown in Figure 1. Since 2006, we observe a growing trend in the number of installed wind farms, with the most significant growth occurring from 2014 onwards. Moreover, according to ANEEL [3],

\footnotetext{
${ }^{1}$ PROINFA was established by Law 10,762 of November 2003, and regulated in 2004

${ }^{2} \mathrm{SIN}$ is a set of facilities and equipment that enable the supply of electricity in the five regions of Brazil.
} 
the installed capacity of wind power grew from $1.00 \mathrm{GW}$ in 2010 to $14.71 \mathrm{GW}$ in 2018 in the country.

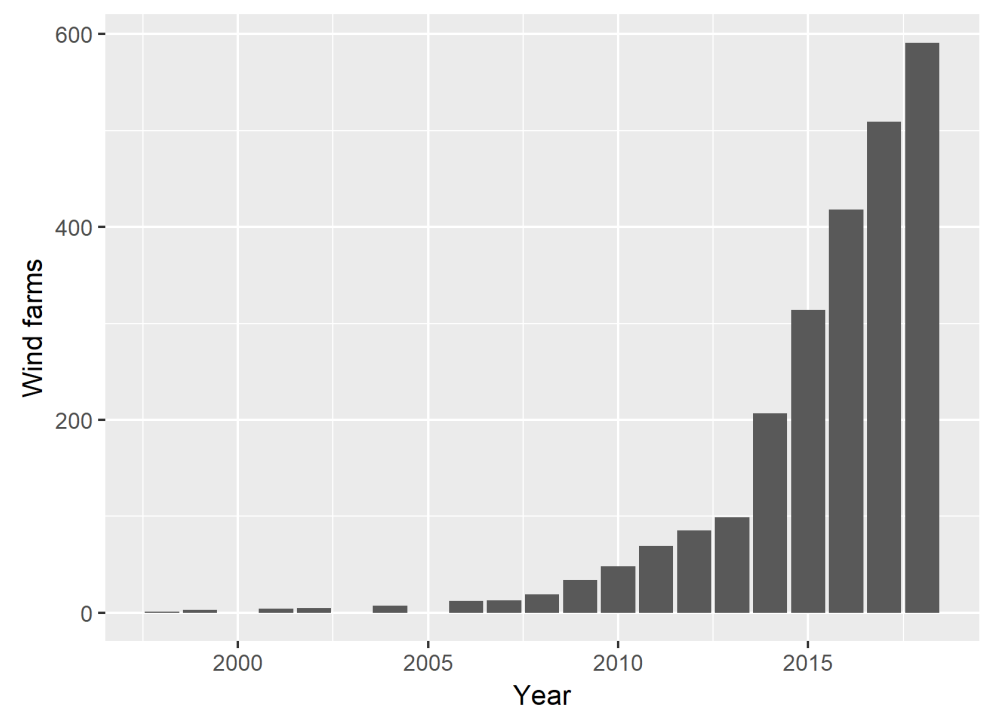

Figure 1: Wind farms in Brazil 1998-2019

Source: ANEEL.

The Energy Research Office (EPE) of the Ministry of Mines and Energy (MME) is responsible for the analyzing and approval of projects for energy auctions. Prior to the auctions, entrepreneurs present their projects, which are then, analyzed based on technical guidelines, such as: i) Anemometric data on wind speed and direction in the locality of the project, from the past three years; ii) The verified interference of wind turbines in neighboring areas; iii) A certification concerning the feasibility of connecting a wind farm to the energy transmission system; iv) Environmental licenses; v) A certification concerning land usage rights. Investors therefore, choose the location of the wind power project, based not only on the possibility of meeting the criteria required to participate in the auction, but also on the factors that maximize the chance of winning the auction. In other words, investors have the autonomy to decide the location of implementation of their wind farm projects. The main factor that determines their choices are the wind conditions, as the speed and occurrence. In Brazil, we observe the prominence of the northeast and the south regions in the location of wind farms operating in 2018, as can be seen in Figure 2

In this paper, we focus on the impact of wind energy in contributing to local development, by analyzing the employment and wages across those municipalities with implemented wind farms. Wind energy projects can improve local welfare through the following set of channels: i) the job creation and income growth prospects of individuals employed in sectors that are affected either directly or indirectly by wind energy; ii) the growth in the incomes of landowners due to land leasing for wind farm implementation; and iii) the possible coexistence of wind farms and 


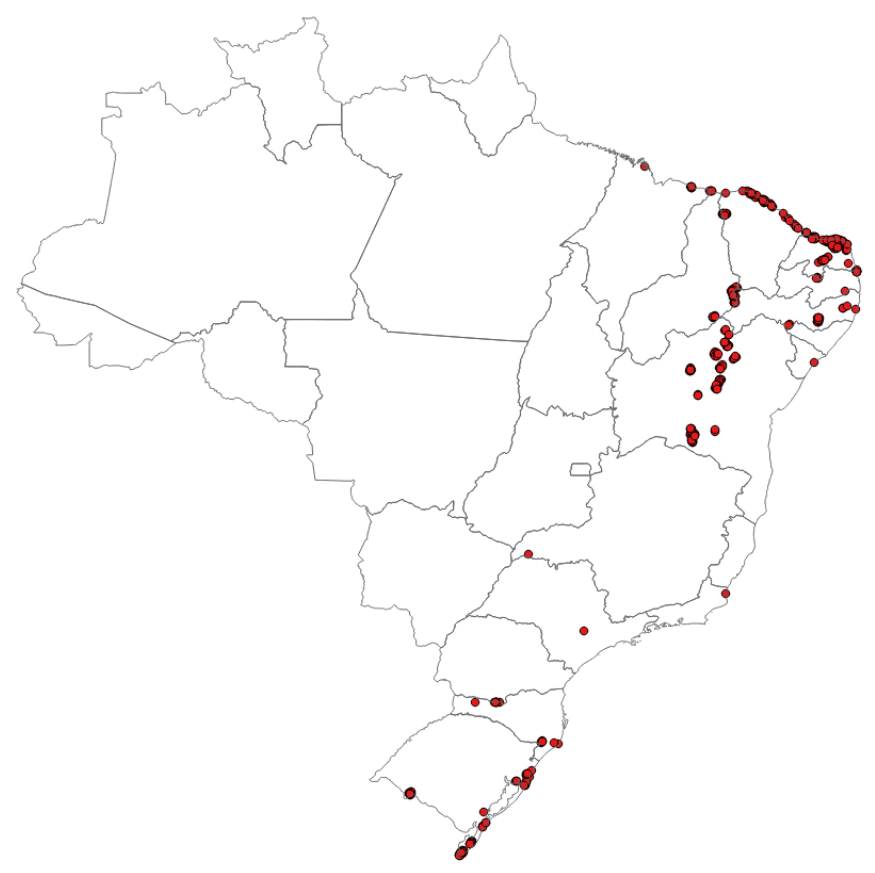

Figure 2: The location of wind farms in Brazil (2018)

Source: ANEEL.

agricultural and livestock activities.

The job creation related to wind projects occurs mainly in the turbine industry. It is estimated that for each megawatt of wind energy implemented per year, fifteen jobs are created, which may either be direct or indirect, and may either be in the wind turbine industry, or supply chain, or wind farm implementation [13]. However, the direct jobs created by the turbine industry are not necessarily allocated to local workers. While the turbine industry is gaining ground in Brazil, equipments can be supplied by factories that are distributed across Brazilian cities or can be supplied by an international manufacturer. Thus, the job creation dynamics of wind power are subject to geographic shifts in the production and sourcing of equipment [24]. The requirements in some countries to source a certain percentage of local equipment, components and services are reshaping the industry. Brazil depicts a trend towards compliance with a minimum of $60 \%$ of wind equipment and components being locally sourced.

Unlike in the turbine industry, the operation of a wind farm does not require a large number of workers. It is estimated that 0.4 jobs are created for each megawatt of wind energy, when the wind plant is in operation or maintenance. Job creation is also high during the construction and implementation of a plant, which on average, lasts from eleven to eighteen months. For example, the construction of a wind farm with a capacity of $50 \mathrm{MW}$ in the northeastern region of Brazil, creates about two hundred direct jobs. Only twenty jobs were created when the plant commenced its operations [13]. 
In Figure 3, we see that the formal employment and average real wages increase in Brazil across all economic sectors from 2002 to 2013, and decline after this period, due to the Brazilian economic crisis. However, we also verify trends specific to each sector. For instance, in the construction sector, the number of workers increased by 150\% from 2002 to 2013, but the average wage over the same period increased by only $50 \%$. On the other hand, in the case of the agricultural sector, while the number of employed workers increased by $60 \%$, the growth in the average wage was $150 \%$, thereby reflecting an improvement in productivity in this sector.

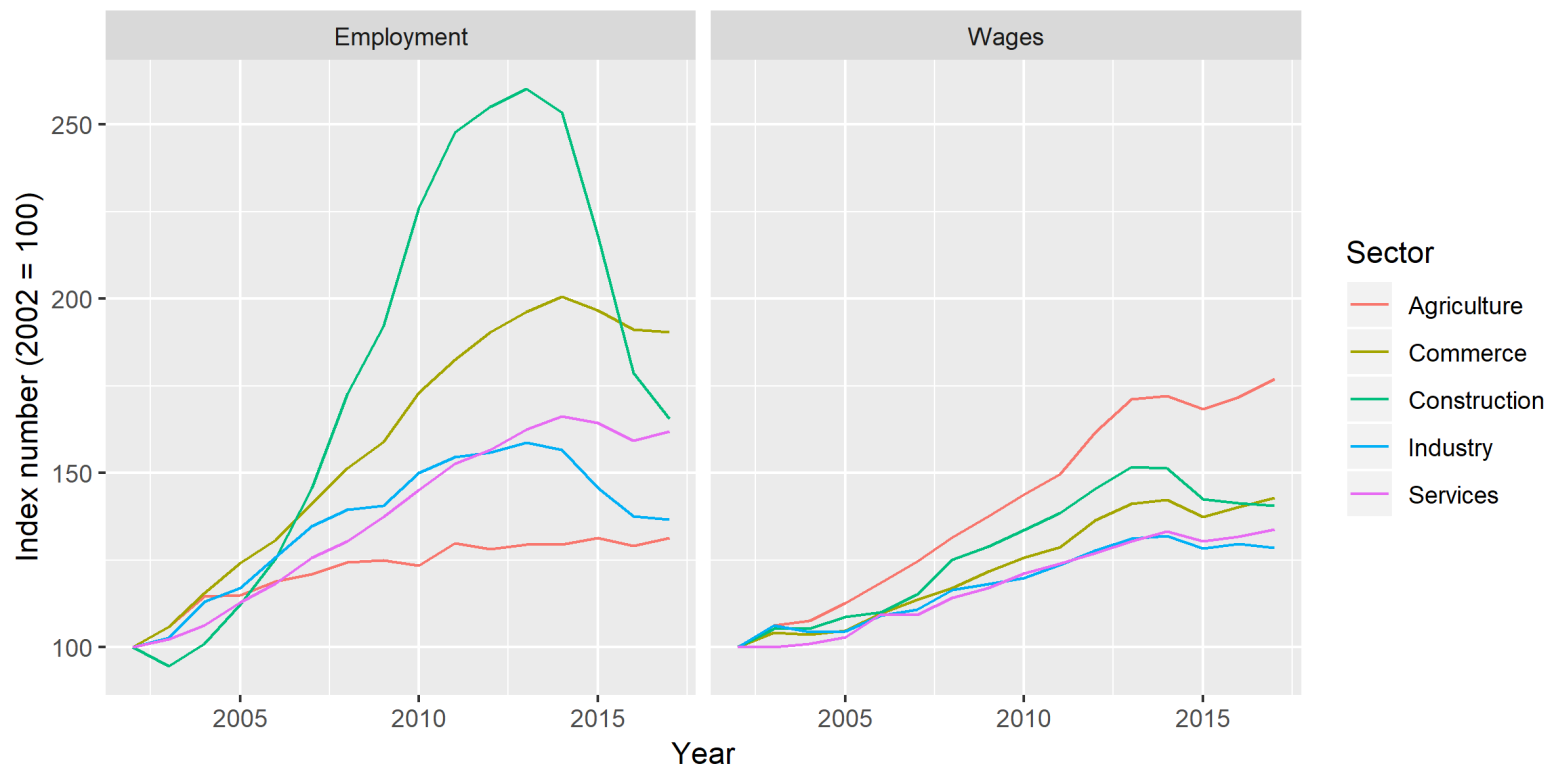

Figure 3: Growth of employment and average wages in Brazil 2002-2018

Source: RAIS.

Notes: Deflated wages to 2002 base year, by the Extended Consumer Price Index (IPCA/IBGE).

\section{Methodology and data}

\subsection{Empirical methodology}

The focal point of our study is the relationship between the implementation of wind farms and the local labor market outcomes. Most empirical applications use the quasi-experimental Difference-in-Differences (DiD) research design, in its canonical form. This method comprises of two groups, namely the treatment and control group, with two periods, pre and post. Known as a two-way fixed effects model with a post treatment dummy variable this specification is used in the identification of the average treatment effect on the treated, under a common trends assumption [19].

However, in this paper we explore the staggered nature of the sequential process of wind farm implantation. Wind farm projects are implemented at a particular point in time, and then 
municipalities remain exposed to this treatment at all times afterwards. Therefore, we consider the identification and estimation of treatment effect parameters using a staggered Differencein-Differences (DiD) approach with: i) multiple time periods, ii) variations in treatment timing, and iii) the parallel trends assumption holding after conditioning on observed covariates.

In the first application of the staggered $\mathrm{DiD}$, we only allow for treatment effect heterogeneity, in terms of the observed covariates and time. We hence, do not consider dynamic treatment effects. This benchmark specification is described in Equation (1):

$$
Y_{m, t}=\alpha+\beta W F_{m, t}+\gamma X_{m, t}+\theta_{m}+\mu_{t}+\varepsilon_{m, t}
$$

where $Y_{m, t}$ indicates some labor market outcome. This could be either the total employment level or the total wage level of the formal sector for municipality $m$ in year $t ; W F_{m, t}$ is a dummy variable that identifies whether municipality $m$ in year $t$, has at least one wind farm; $X_{m, t}$ is a vector of municipal characteristics. $\theta_{m}$ is the fixed effects of municipalities. $\mu_{t}$ is a year fixed effect. $\varepsilon_{m, t}$ is a random term; and $\alpha, \beta$ and $\gamma$ are parameters. Under this strategy, we consider the same municipality as a treatment unit in certain periods and a control unit in others. The source of variation that allows for the identification of the effect of wind farms is the distinct timing of implementation across municipalities.

This staggered DiD has relevant advantages in comparison to a two-way fixed effects model with a binary post-treatment variable. The latter estimator is a weighted average of all possible two-group and two-period DiD estimators in the data, and it is biased if the effects change over time, since it does not isolate the contemporaneous effect of the intervention [19].

On the other hand, the staggered DiD presents two main potential source of problems: omitted variable bias and the dynamic endogeneity, that is, the implementation of a wind farm may respond to labor market conditions within a municipality. We address the first concern, by conditioning on the observed covariates and on the fixed effects in the regression models, as well as adding interaction terms between the control variables and a linear time trend to capture trends specific to each municipality. The use of the fixed-effects and linear temporal trends are partial solutions that additionally deal with the second source of concern, namely dynamic endogeneity.

In the second application of the staggered DiD, we consider the dynamic treatment effects. We then use an extension of the DiD by including five leads and lags of treatment as regressors, in an event study design, to estimate the average dynamic effects of discrete shocks and nontransient treatments. This second empirical exercise allows us to analyze the extent and duration of the effectiveness of wind farm implementation in increasing local employment and wages. Therefore, we adopt a flexible coefficient approach similar to Jacobson et al. [25], summarized by a specification that allows for pre- and post-treatment, jointly with the contemporaneous estimation of the Average Treatment Effect (ATE). Equation (2) describes the implemented event study: 


$$
Y_{m, t}=\alpha+\sum_{i=1}^{I} \beta_{p r e, i} W F_{m, t+i}+\sum_{j=0}^{J} \beta_{j} W F_{m, t-j}+\gamma X_{m, t}+\theta_{m}+\mu_{t}+\varepsilon_{m, t}
$$

where $W F_{m, t-j}$ are year-specific indicators that denote whether municipality $m$ in year $t-j$ has at least one wind farm implemented; and $W F_{m, t+i}$ indicates whether municipality $m$ will have wind farms implemented in $i$ years in future periods. Following the usual strategy in event study analysis, we test the significance of the coefficients $\beta_{\text {pre }, i}$, as there may be pre-existing trends in labor market outcomes. The inclusion of $\beta_{j}$ allows for a lag in the effects of wind farm implementation and the treatment heterogeneity by exposure time.

It is worth mentioning that the reliability of the causal interpretation of the estimated effects in an event study design, depends on the following relevant assumptions or exclusion restrictions: i) conditional parallel trends are valid, implying that in the absence of treatment, similar municipalities would follow similar employment and wage trends; ii) no anticipation of the treatment, implying that municipalities have no prior knowledge concerning the probability of the implementation of wind farms over time and hence, do not respond proactively prior to the intervention ${ }^{3}$; and iii) no selective treatment timing, and no causal effect on the outcome, with respect to an early versus a later adoption [19]. The violation of these assumptions implies that caution must be exercised, while interpreting the results.

Many empirical studies utilize a model for the realized outcome that depends solely on contemporaneous treatment exposure and not on the actual adoption date or treatment exposure in other periods, implicitly considering the validity of these assumptions. Otherwise, in a discussion regarding event study results, these restrictions are explicitly admitted as assumptions that do not automatically hold.

Even though event studies are increasingly used as an extension of DiD design, it is relatively a new approach, such that a formal framework concerning identifying assumptions is still being developed. Some studies focus on understanding what causal parameter the coefficient of a twoway fixed effects model represents, under treatment effect heterogeneity [5, 9, 15, 19]. It is a common consensus that it usually represents a weighted sum of various average treatment effects. These weights are partially determined by the estimation procedure that one adopts [12].

Finally, we cluster the standard errors at the municipal level to account for serially correlated and heteroscedastic errors in all regressions [7].

\subsection{Data}

Our database is built at the municipal level, the smallest administrative unit in Brazil. We aggregate two ANEEL databases: the Georeferenced Information System of the Electricity Sector (SIGEL) and the Generation Information Data (BIG). We extract information on the stage of

\footnotetext{
${ }^{3}$ We expect that this assumption holds true, since projects are evaluated based on technical guidelines and that project approval is necessary to be able to participate in an energy auction.
} 
implementation, the location of wind farms, and the capacity of implemented wind farms based on SIGEL data, which presents georeferenced information. Data from BIG presents information regarding the date of commencement of operations for implemented wind farms.

We consider wind farms with operating status and disregard deactivated wind farms and power plants with an installed capacity of less than or equal to 100 kilowatts $(\mathrm{kW})$, since these plants are not implemented for commercial purposes [3]. The literature on wind farms effects finds that the impact may be significant during the construction phase. However, we do not have access to this information from our data sources. Thus, we consider as the intervention period, the exact moment in which the first established wind farm in a municipality commences operations. In section 4.4, we estimate a regression model based on the event study design in which we alternatively consider the construction of the first wind farm in a municipality as the intervention event. We assume that on average, this phase lasts two years 4 It is worth noting that in this study, we do not take into account the effects of a continuous treatment, that is, a dose response from other wind farms implemented in future, or the energy potential of the implemented wind farms.

The aim of this article is to analyze the relationship between the timing of wind farm implementation and labor market outcomes, which are variables that drive social welfare and local development. The dependent variables are the total employment levels and the total wage levels across the municipalities. We use longitudinal and administrative data from the Annual Social Information Report (RAIS) of the Brazilian Ministry of Economy to build these labor market outcomes at the municipal level. The RAIS data is reported by firms and hence, only covers the formal sector of the labor market. In addition to variables that represent the total of employment and wages, used for the general estimations, we construct employment and wage variables for: i) economic sectors, such as industry, construction, commerce and services, and agriculture. These categories of sectors are defined as per the groups prescribed by the Brazilian Occupational Classification (CBO); ii) three categories of worker educational levels, namely elementary, high school and higher education; and iii) three different categories of firm sizes: small (firms with up to 49 employees), medium (firms with more than 49 and up to 499 employees) and large (firms with more than 499 employees). The employment and wages of these specific sectors and groups are utilized in heterogeneity analysis.

We also extract data for some control variables to perform conditional estimations. We are thus, seeking to ensure some degree of comparability of municipalities in the treatment and control groups. The first set of variables is comprised of political controls, introduced for the purpose of controlling for differences across municipalities in terms of political effort, investment and resource allocation. We obtain data on the current net expenditure from the Finances of Brazil (FINBRA/STN) database. Data on political affiliations of the mayors of municipalities and of the Brazilian president. These allow us to construct a binary variable indicating the

\footnotetext{
${ }^{4}$ Technical reports shows that in Brazil, the duration of the construction and implementation of a wind plant on an average, lasts from eleven to eighteen months.
} 
equality of political affiliations. Furthermore, we obtain data regarding the educational levels of mayors of municipalities 5 All such data was available from the Brazilian Superior Electoral Court (TSE).

Other municipal socioeconomic characteristics are considered as control variables for the changes that may occur simultaneously during the implementation of wind farms. We construct a proxy for the percentage of poor families at the municipal level based on data of the beneficiary families of the Bolsa Familia Program (PBF) from the Brazilian Ministry of Citizenship, and on the total number of households from the IBGE. Additionally, the ratio of the gross added value of agriculture to the total gross added value is obtained from the IBGE, to capture the opportunity cost of land usage in wind farm implementation.

In addition, we use data on the average annual wind speed (in meters per second) from a height of 50 meters, from the National Institute of Space Research (INPE), to estimate the propensity score of a municipality has at least one implemented wind farm, and also to select municipalities with wind speeds of above 3.5 meters per second. This information is utilized to conduct robustness checks. Table 1 depicts the descriptive statistics for the dependent and control variables used in this study for the group of municipalities in the treatment group that have a wind farm that was implemented in some year from 2004 to 2016, and for the municipalities in the control group. Table 1 presents the average of variables, as well as, the results of twosample t-test for equal means. We construct this table without the establishment of sample selections. We verify statistically significant mean differences in wages and in the majority of the control variables in the baseline year, across the two groups of municipalities considered, thereby justifying conditional analysis. Besides, these differ in terms of population size (used as regression weights), and in terms of area and wind speed of the municipality.

Finally, we conduct robustness checks also through the analysis of the possibility of the impact of wind power implementation extending beyond the boundaries of the municipality in which the wind farm is located. Spillover effects may occur due to the migration of workers from neighboring municipalities, who accept a job opportunity in the location of implementation of wind farms, but continue to live in their cities. Another possibility already mentioned in the literature is that wind energy projects also increases the demand for goods and services and these effects can extend beyond the boundaries of a municipality.

In order to control for such spillover effects, we construct distance measures from the location coordinates of wind farms. Furthermore, we consider as treatment group those municipalities whose administrative center is located within these buffers created on the basis of the distance measures. Buffers are constructed by considering distances of $50 \mathrm{~km}, 100 \mathrm{~km}, 150 \mathrm{~km}$, and $200 \mathrm{~km}$, from the location coordinates of wind farms. Appendix A provides the number of municipalities that are considered as treatment units by year and by distance buffer. It is important to note that under a specific distance measure, a municipality can be included in the

\footnotetext{
${ }^{5}$ This information is not available for 2004 .
} 
Table 1: Descriptive analysis

\begin{tabular}{lcccc}
\hline Variable & Control & Treatment & Mean Diff & Source \\
\hline Employment & & & & \\
Total & 5.61 & 8.47 & -2.86 & RAIS \\
Sectors & & & & \\
Industry & 1.15 & 1.39 & -0.24 & RAIS \\
Construction & 0.20 & 0.35 & -0.16 & RAIS \\
Commerce and Services & 4.03 & 6.42 & -2.39 & RAIS \\
Agriculture & 0.23 & 0.32 & -0.08 & RAIS \\
Schooling of workers & & & & \\
Elementary & 2.31 & 3.39 & -1.08 & RAIS \\
High school & 2.26 & 3.54 & -1.28 & RAIS \\
College & 1.04 & 1.54 & -0.50 & RAIS \\
Size of firms & & & & \\
Small & 2.14 & 3.24 & -1.09 & RAIS \\
Medium & 1.56 & 2.35 & -0.79 & RAIS \\
Large & 1.90 & 2.89 & -0.98 & RAIS \\
Wages & & & & \\
Total & 12.78 & 13.16 & $-0.38^{*}$ & RAIS \\
Sectors & & & & \\
Industry & 9.41 & 9.58 & -0.16 & RAIS \\
Construction & 4.82 & 6.04 & $-1.23^{* *}$ & RAIS \\
Commerce and Services & 12.34 & 12.79 & $-0.45^{* *}$ & RAIS \\
Agriculture & 8.72 & 8.67 & 0.05 & RAIS \\
Schooling of workers & & & & \\
Elementary & 11.85 & 12.04 & -0.19 & RAIS \\
High school & 11.71 & 12.16 & $-0.45^{* *}$ & RAIS \\
College & 10.86 & 11.52 & $-0.67^{* *}$ & RAIS \\
Size of firms & & & & \\
Small & 11.55 & 11.64 & -0.09 & RAIS \\
Medium & 11.06 & 11.46 & -0.40 & RAIS \\
Large & 4.23 & 7.64 & $-3.41^{* * *}$ & RAIS \\
Control variables & & & & \\
Poverty rate & 0.21 & 0.31 & $-0.09^{* * *}$ & MDS and IBGE \\
Schooling of mayor & 0.26 & 0.19 & $0.07^{* * *}$ & IBGE \\
Political party & 12.08 & 12.15 & -0.07 & TSE \\
Net expenditures & 0.07 & 0.09 & -0.02 & TSE \\
$\begin{array}{l}\text { Population } \\
\text { Area }\end{array}$ & 15.70 & 16.21 & $-0.51^{* * *}$ & FINBRA/STN \\
Wind speed & 9.37 & 10.01 & $-0.65^{* * *}$ & IBGE \\
Number of municipalities & 6.20 & 6.47 & $-0.27^{*}$ & IBGE \\
\hline value & 6.32 & $-1.20^{* * *}$ & INPE \\
\hline
\end{tabular}

Notes: Wages, net expenditures, area, and population of municipalities are log transformed. Employment variables are in thousands. Means of the mayor's schooling and of the variable indicating equality of political parties of the mayor and president are calculated for 2005 because they are unavailable for the baseline year.

treatment group more than once, that is, there may be an overlap among the influence areas of implemented wind farms. In this case, we consider the municipality as belonging to the treatment group, since the year of implementation of the eldest wind farm. 


\section{Results and discussions}

\subsection{General results of the staggered DiD}

The first part of our results focuses on the general estimates from the staggered DiD, in which we allow for treatment effect heterogeneity in covariates and time, based on Equation (1) of the concerned empirical methodology. We perform conditional estimations and test specifications under a set of control variables and fixed effects. Table 2 presents the estimates of the relationship between the presence of wind farms and the total employment and wages.

We test seven specifications. The column (1) of Table 2 depicts the results from the unconditional staggered DiD. The column (2) takes into account control variables for political and socioeconomic characteristics. The column (3) depicts the results of a population-weighted regression that accounts for the interrelation of the variance of labor market outcomes and population size. The columns (4) and (5) consider the fixed effects for Brazilian states and economic areas defined by the IBGE, respectively ${ }^{6}$ In the columns (6) and (7), we include municipalityspecific linear and non-linear time trends, controlling for any systematic differences and specific trends across locations prior to the intervention.

This first set of results indicates a positive and statistically significant relationship between the timing of wind farm implementation and the total employment and wage levels of municipalities. As employment and wages are in logarithmic form, the coefficients can be interpreted as semi-elasticities. The unconditional staggered DiD estimates an effect of approximately $84 \%$ on employment and $97 \%$ on wages. The conditional analysis undertaken with the inclusion of local characteristics of municipalities and the fixed effects for states and economic areas, determine a considerable reduction in the coefficients. Conditional point estimates utilizing specification (4) suggest that wind farm implementation may be associated with a $27 \%$ increase in employment and a $34 \%$ increase in wages. We chose this specification as our benchmark result since in Brazil, a broad set of public policies that could affect employment and wages are at least partially determined at the state level, and it is less expected that policies at the level of economic areas will occur because it would depend of regional integration of states.

\footnotetext{
${ }^{6}$ In 2017, the IBGE established 510 economic areas, that are areas assisted by nearby urban centers to meet the immediate needs of populations, such as demand for durable and non-durable goods and services; job search; and provision of public and judicial services, among others (IBGE)
} 


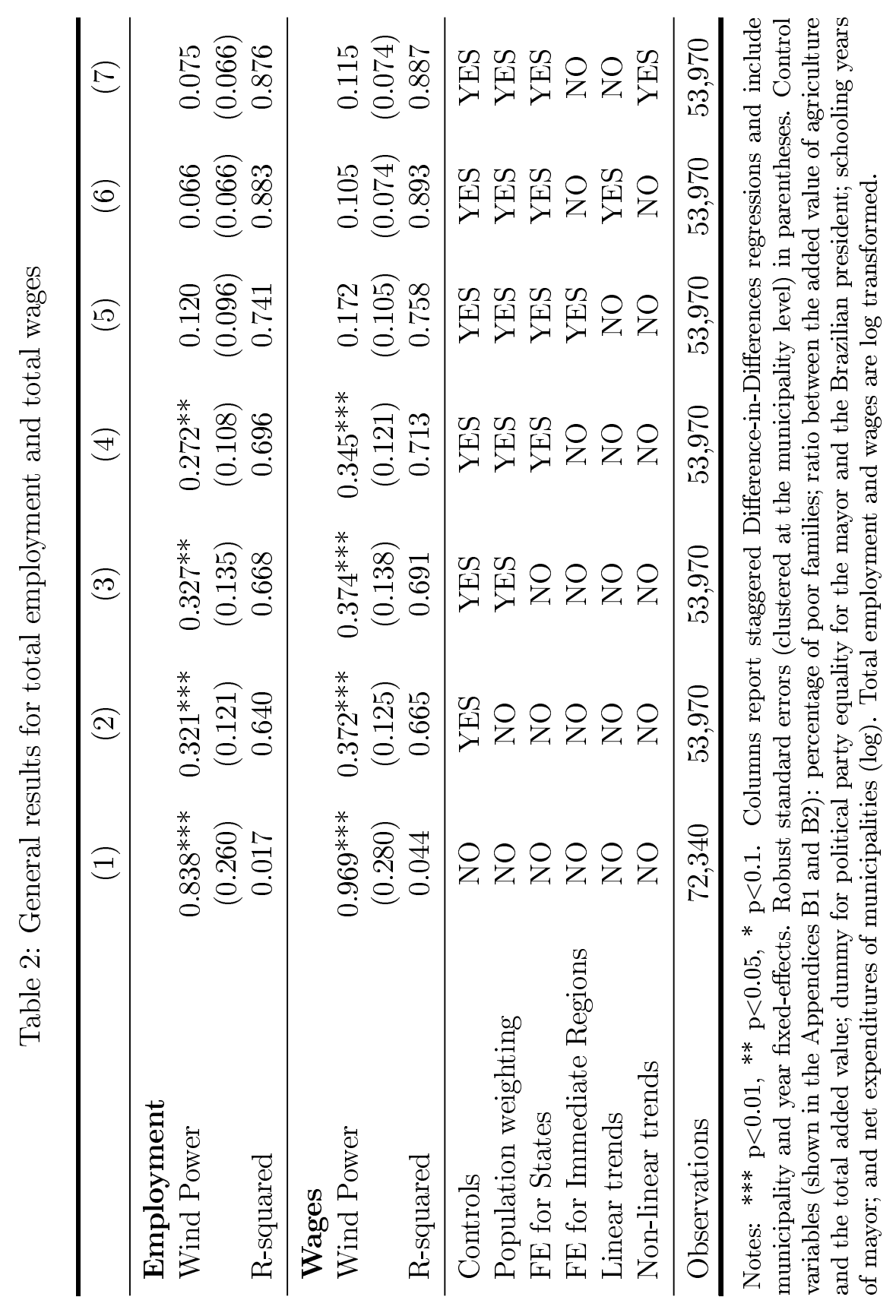


Additionally, linear and non-linear trends cause a decline in the coefficients thereby leading to statistically non-significant results. This indicates evidence of the violation of the conditional parallel trend assumption, since the municipalities in the treatment and control groups could depict distinct employment and wages paths prior to the intervention. While we do not ignore this aspect, we deal with the pre-existing trends in outcomes through an event study approach, by accounting for dynamic treatment effects.

\subsubsection{Robustness checks: sample selections and spillover effects}

The first part of the robustness checks presents the results of such checks that deal with a major concern that remained unaddressed in the general results, namely the degree of comparability or similarity of municipalities in the treatment and control groups. The absence of common support between treated and non-treated municipalities can generate misleading results. We test alternative samples of municipalities in order to find comparable groups. We use these samples and the benchmark specification (4) of Table 2 to estimate the treatment effects and verify the sensitivity of the results.

The alternative samples constitute the following: i) the set of municipalities that are not state capitals; ii) the set of municipalities located outside metropolitan areas (MAs); and iii) the set of municipalities located outside the northern region of Brazil. This region has the lowest annual average wind speed and no implemented wind farms up to 2018. State capitals and MAs are characterized by specific economic and demographic dynamics.

Next, we restrict the control and treatment groups to municipalities with an average annual wind speed of above $3.5 \mathrm{~m} / \mathrm{s}$, the minimum required for the operation of a wind turbine. Additionally, we implement a Propensity Score Matching (PSM) approach, by estimating a probit model for the probability of the municipality presenting at least one wind farm, in which we include, as explanatory variables, the average annual wind speed, and the area of municipalities. Finally, we restrict the period analyzed for 2009-2016, since this is the period with a substantial increase in the implementation of wind farms, thus reducing the weight of a long baseline period with a low number of wind farms. 


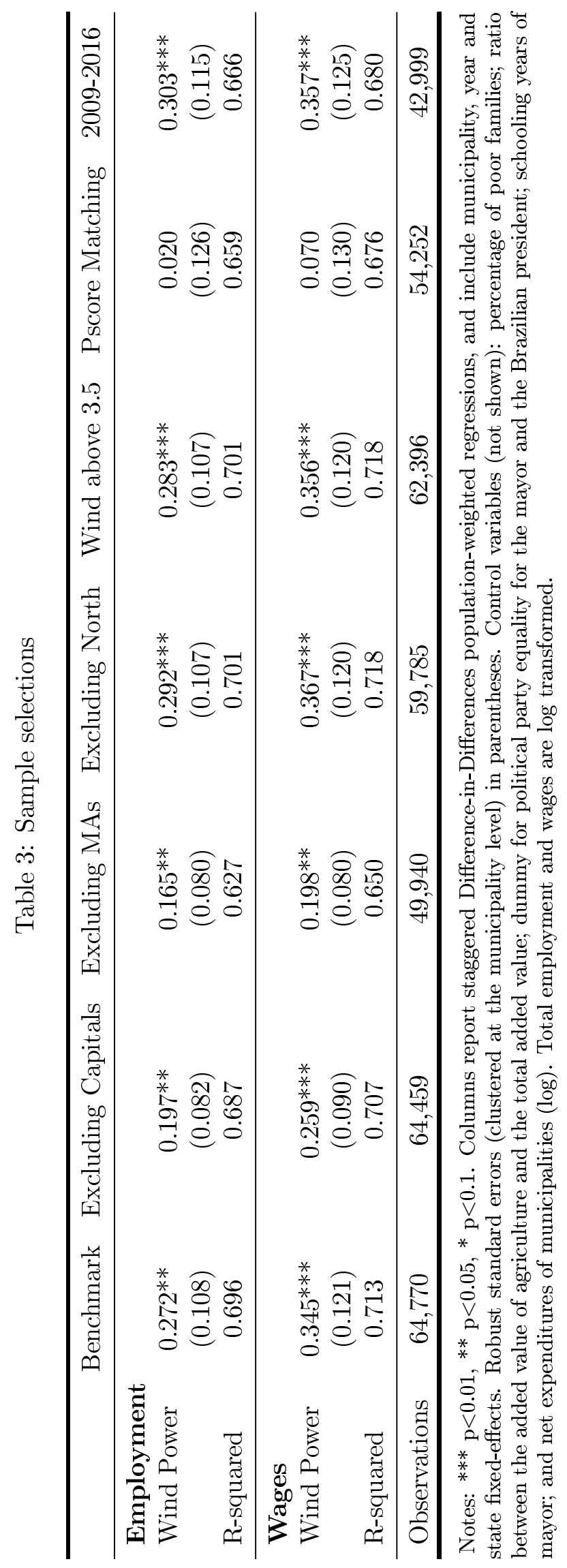


The Table 3 presents the results of this first set of robustness checks and allows us to verify whether our results are sensitive to alternative samples. We observe that the results estimated with the exclusion of municipalities in the northern region, as well as municipalities with annual wind speed below $3.5 \mathrm{~m} / \mathrm{s}$, and the results estimated for the 2009-2016 period, are similar to those under the benchmark specification, with the impact on employment ranging from $27 \%$ to $30 \%$, and the impact on wages ranging from $34 \%$ to $37 \%$. On the other hand, the exclusion of municipalities that are state capitals and cities located in metropolitan areas affects the estimated coefficients more significantly. The effects remain positive and statistically significant, but decline to approximately $20 \%$ and $16 \%$ for employment, and to $26 \%$ and $20 \%$ for wages, excluding, state capitals and MAs. Hence, the results become statistically non-significant but remain positive, when we establish the common support between treated and control municipalities, weighting the regression by the propensity score.

The second part of the robustness checks comprises of the analysis of another source of concern that remained unaddressed in the general results, namely the spillover effects, which is the possibility of the impacts of wind power implementation extending beyond the boundaries of municipalities where the wind farm is located.

In order to control for such spillover effects, we construct distance measures from the location coordinates of wind farms, and consider as treatment units, the municipalities whose administrative centers are located within these buffers created on the basis of specific distance measures, as explained in Subsection 3.2. Figure 4, depicts the number and location of municipalities in the treatment group, if we consider the buffers constructed on the basis of distances of $50 \mathrm{~km}, 100$ $\mathrm{km}, 150 \mathrm{~km}$, and $200 \mathrm{~km}$, from 2004 to 2016. This figure enables the verification of the expansion of the number of treatment units relative to an increase in the distances especially since 2014 .

Table 4 presents the results for estimates that consider the expansion of treatment units based on spillover effects. The benchmark results are again generated under specification (4) of Table 2. We found that this new definition of treatment units lowers the effects of wind energy on employment and wages. Considering the distance buffer of $50 \mathrm{~km}$, the impact of wind energy on employment and wage levels are approximately $13 \%$ and $16 \%$, respectively. These effects are maximal at a distance buffer of $100 \mathrm{~km}$, with impacts of $7 \%$ and $9 \%$ for employment and wages, respectively.

Also, as a final robustness check, we combine certain sample selections such as the exclusion of state capitals and municipalities in metropolitan areas, and the inclusion of control for spillover effects, by utilizing the $100 \mathrm{~km}$ distance buffer. This combination allows for the improvement in the degree of comparability of municipalities in treatment and control groups, as well as the consideration of the possibility of the extension of impacts beyond the borders of municipalities. The results are presented in the last column of Table 4. We observe a decline in the estimated coefficients, implying an average treatment impact of wind power of approximately $10 \%$ on employment and $13 \%$ on wages. 

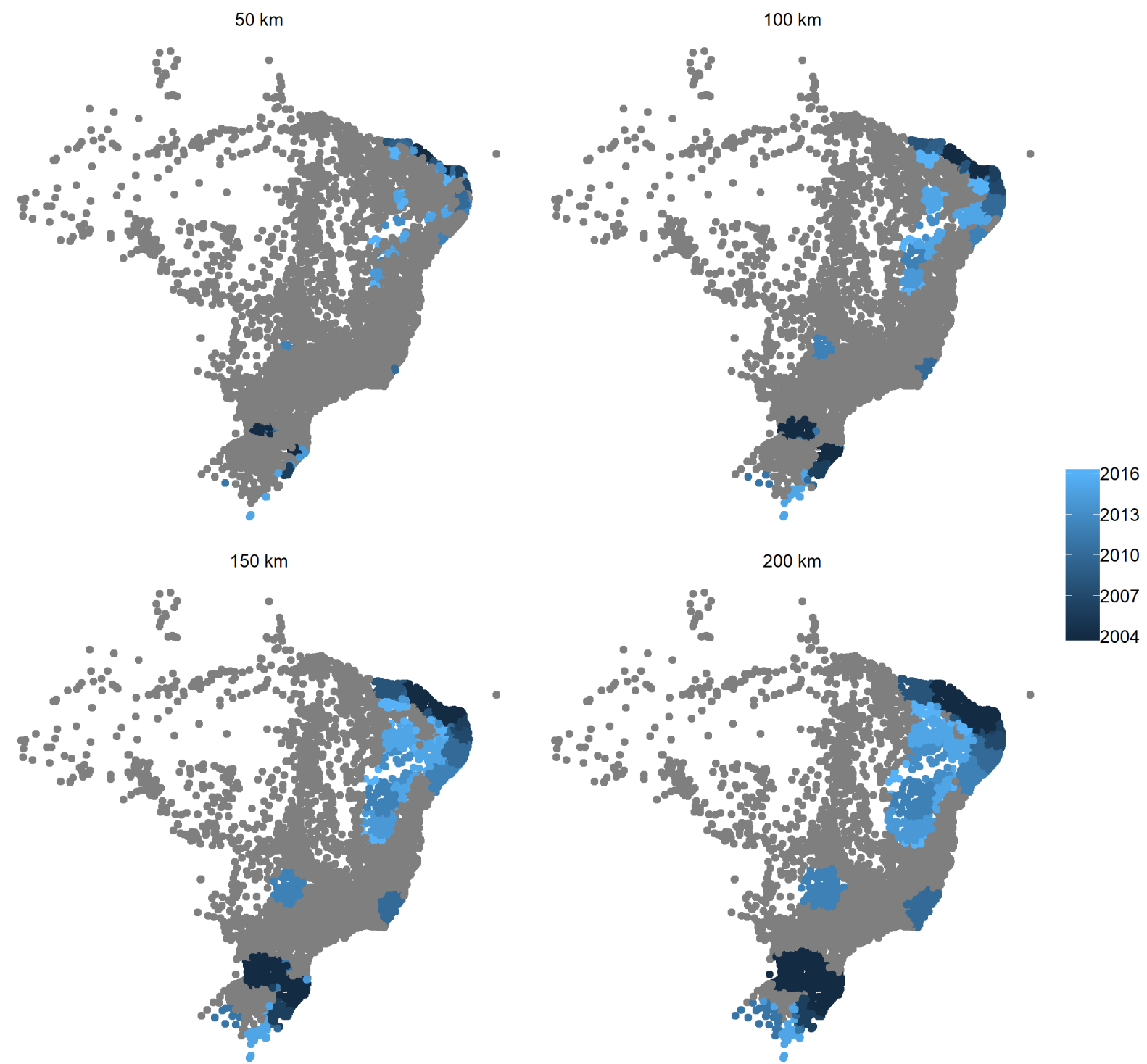

Figure 4: Treatment units based on distance

Note: The points on maps correspond to the geographical location of the administrative center of the municipalities.

\subsubsection{Heterogeneity of the treatment effects}

In this subsection, we address the heterogeneity of local impact of wind energy on the employment and wages of workers across economic sectors (industry, construction, commerce and services, and agriculture), educational levels of workers (elementary, middle and higher education) and firm sizes (small, medium and large). Observing the heterogeneity of the average treatment effects enables the drawing of inferences regarding the potential of wind energy in contributing to local development, since the improvement in the labor market conditions for disadvantaged groups could also imply improvements in social welfare and a reduction in social inequalities. 
Table 4: Spillover effects: treatment units based on distance

\begin{tabular}{|c|c|c|c|c|c|c|}
\hline & Benchmark & $50 \mathrm{~km}$ & $100 \mathrm{~km}$ & 150 km & $200 \mathrm{~km}$ & Selections \& spillover \\
\hline \multicolumn{7}{|l|}{ Employment } \\
\hline Wind Power & $\begin{array}{c}0.272^{* *} \\
(0.108)\end{array}$ & $\begin{array}{c}0.131^{* * *} \\
(0.044)\end{array}$ & $\begin{array}{c}0.196^{* * *} \\
(0.029)\end{array}$ & $\begin{array}{c}0.138^{* * *} \\
(0.024)\end{array}$ & $\begin{array}{c}0.069^{* * *} \\
(0.022)\end{array}$ & $\begin{array}{c}0.098^{* * *} \\
(0.030)\end{array}$ \\
\hline R-squared & 0.696 & 0.696 & 0.696 & 0.696 & 0.696 & 0.625 \\
\hline \multicolumn{7}{|l|}{ Wages } \\
\hline Wind Power & $\begin{array}{c}0.345^{* * *} \\
(0.121)\end{array}$ & $\begin{array}{c}0.164^{* * *} \\
(0.047)\end{array}$ & $\begin{array}{c}0.232^{* *} \\
(0.031)\end{array}$ & $\begin{array}{c}0.174^{* * *} \\
(0.026)\end{array}$ & $\begin{array}{c}0.092^{* * *} \\
(0.024)\end{array}$ & $\begin{array}{c}0.127^{* * *} \\
(0.031)\end{array}$ \\
\hline R-squared & 0.713 & 0.713 & 0.714 & 0.714 & 0.714 & 0.648 \\
\hline Observations & 64,770 & 64,770 & 64,770 & 64,770 & 64,770 & 49,904 \\
\hline
\end{tabular}

Notes: ${ }^{* * *} \mathrm{p}<0.01,{ }^{* *} \mathrm{p}<0.05,{ }^{*} \mathrm{p}<0.1$. Columns report staggered Difference-in-Differences population-weighted regressions and include municipality, year and state fixed-effects. Robust standard errors (clustered at the municipality level) in parentheses. Control variables (not shown): percentage of poor families; ratio between the added value of agriculture and the total added value; dummy for political party equality for the mayor and the Brazilian president; schooling years of mayor; and net expenditures of municipalities (log). Total employment and wages are $\log$ transformed. Sample selection: exclusion of capitals and MAs.

Table 5 depicts the results of the heterogeneous impacts on employment and Table 6, for wages. We estimate these subgroup effects following the specification, sample selections and spillover effects of the last column of Table 4. Thus, the average treatment effect depicted in the second column of tables 5 and 6, denoted as Total, is a weighted sum of the average treatment effects estimated for the sectors, or for the educational levels, or for the size of firms, in which weights are determined by the share of employment or by the size of the total wages of a specific sector or group.

The results suggest that the implementation of wind farms in municipalities increases the employment in industry, construction, and agriculture. The largest proportional impact on employment levels was found in the agricultural sector (64\%). Furthermore, for wages, we verify effects in all the economic sectors, including commerce and services, with the largest proportional impact on wages also found in the agricultural sector (131\%) and industry (67\%). These results are consistent with the literature, since Blanco and Rodrigues [8] found that wind energy creates a significant number of direct jobs, mainly in industry. Simas and Pacca [29] depicted critical local impacts during the construction phase of wind farms, for Brazil. Additionally, the results are in keeping with Bergmann et al. [6], such that the socioeconomic benefits of renewable energy sources was largest in rural areas. Moreover, as emphasized in Section 2, wind energy can improve local welfare by increasing the income of landowners due to land leasing for wind farm implementation and the possible coexistence of agricultural and livestock activities and wind farms. Therefore, impacts of wind power could be expected in the agricultural sector.

Indeed, it is possible to observe positive and statistically significant effects of wind energy on the employment and wages of workers with elementary and high school educational levels. This 
Table 5: Heterogeneity: Employment

\begin{tabular}{lccccc}
\hline Sector & Total & Industry & Construction & Comm and Serv & Agriculture \\
\hline Wind Power & $0.098^{* * *}$ & $0.394^{* * *}$ & $0.116^{*}$ & 0.026 & $0.637^{* * * *}$ \\
& $(0.030)$ & $(0.075)$ & $(0.060)$ & $(0.028)$ & $(0.078)$ \\
R-squared & 0.625 & 0.574 & 0.500 & 0.608 & 0.535 \\
\hline Schooling & Total & Elementary & High school & College & \\
\hline Wind Power & $0.098^{* * *}$ & $0.096^{* *}$ & $0.099^{* * *}$ & 0.004 & \\
& $(0.030)$ & $(0.039)$ & $(0.033)$ & $(0.035)$ & \\
R-squared & 0.625 & 0.579 & 0.624 & 0.572 & \\
\hline Firm size & Total & Small & Medium & Large & \\
\hline Wind Power & $0.098^{* * *}$ & $0.208^{* * *}$ & $0.521^{* * *}$ & -0.068 & \\
& $(0.030)$ & $(0.047)$ & $(0.080)$ & $(0.105)$ & \\
R-squared & 0.625 & 0.626 & 0.317 & 0.470 & \\
\hline Observations & 49,904 & 49,904 & 49,904 & 49,904 & 49,904 \\
\hline
\end{tabular}

Notes: ${ }^{* * *} \mathrm{p}<0.01,{ }^{* *} \mathrm{p}<0.05,{ }^{*} \mathrm{p}<0.1$. Columns report staggered Difference-in-Differences populationweighted regressions and include municipality, year and state fixed-effects. Robust standard errors (clustered at the municipality level) in parentheses. Control variables (not shown): percentage of poor families; ratio between the added value of agriculture and the total added value; dummy for political party equality for the mayor and the Brazilian president; schooling years of mayor; and net expenditures of municipalities $(\log )$. Total employment and wages are log transformed. Sample of municipalities: exclusion of capitals and MAs, and considering spillover effects with the $100 \mathrm{~km}$ buffer.

result could evidence that the expansion of wind power generation in Brazil could have additional implications through favorable labor market outcomes of less-skilled workers, providing local development oriented to increasing welfare and reducing social inequality.

The last part of tables 5 and 6 depict the heterogeneity of the average treatment effects in terms of the size of firms in which the workers are employed. We find positive and statistically significant coefficients only for small and medium sized firms, which could also constitute evidence of the relevant impact of the contribution of wind energy to the development of municipalities, since the most positively affected are the smallest employers.

\subsection{Event study design: the dynamic treatment effects}

In the second part of the results, we apply the staggered DiD with the inclusion of dynamic treatment effects of wind farm implementation. Thus, we adopt an event study framework as described in Equation (2), by including as regressors, five treatment leads, and lags. This empirical exercise allows us to analyze the extent and duration of the effectiveness of wind farm implementation in increasing local employment and wages. Moreover, under this extension of the DiD, we deal with and test pre-existing trends in the labor market outcomes of municipalities. The main advantage of an event study design is the explicit consideration of time heterogeneity 
Table 6: Heterogeneity: Wages

\begin{tabular}{lccccc}
\hline Sector & Total & Industry & Construction & Comm and Serv & Agriculture \\
\hline Wind Power & $0.127^{* * *}$ & $0.671^{* * *}$ & $0.368^{* * *}$ & $0.072^{* *}$ & $1.306^{* * *}$ \\
& $(0.031)$ & $(0.135)$ & $(0.142)$ & $(0.029)$ & $(0.152)$ \\
R-squared & 0.648 & 0.468 & 0.406 & 0.629 & 0.520 \\
\hline Schooling & Total & Elementary & High school & College & \\
\hline Wind Power & $0.127^{* * *}$ & $0.115^{* * *}$ & $0.130^{* * *}$ & 0.045 & \\
& $(0.031)$ & $(0.042)$ & $(0.034)$ & $(0.042)$ & \\
R-squared & 0.648 & 0.576 & 0.643 & 0.552 & \\
\hline Firm size & Total & Small & Medium & Large & \\
\hline Wind Power & $0.127^{* * *}$ & $0.179^{* * *}$ & $0.977^{* * *}$ & -0.085 & \\
& $(0.031)$ & $(0.048)$ & $(0.156)$ & $0.203)$ & \\
R-squared & 0.648 & 0.629 & 0.276 & 0.450 & \\
\hline Observations & 49,904 & 49,904 & 49,904 & 49,904 & 49,904 \\
\hline
\end{tabular}

Notes: ${ }^{* * *} \mathrm{p}<0.01,{ }^{* *} \mathrm{p}<0.05,{ }^{*} \mathrm{p}<0.1$. Columns report staggered Difference-in-Differences populationweighted regressions and include municipality, year and state fixed-effects. Robust standard errors (clustered at the municipality level) in parentheses. Control variables (not shown): percentage of poor families; ratio between the added value of agriculture and the total added value; dummy for political party equality for the mayor and the Brazilian president; schooling years of mayor; and net expenditures of municipalities $(\log )$. Total employment and wages are log transformed. Sample of municipalities: exclusion of capitals and MAs, and considering spillover effects with the $100 \mathrm{~km}$ buffer.

through dynamic treatment effects. In addition, this approach does not assume that the realized outcome depends solely upon the contemporaneous treatment exposure.

We present the main results of the event study not only in Figure 5 , but also in the form of regression tables in Appendices B.1 and B.2. In Figure 5, we plot in the same chart the estimated pre- and post-intervention coefficients, $\beta_{\text {pre }, i}$ and $\beta_{j}$. In this figure, we present a graphical depiction of the estimation results of Equation (2) under the benchmark specification, since this specification meet the common trend criteria. This specification considers population weights, covariates, and fixed effects for Brazilian states. However, section B of the Appendices comprises of tables under regressions with: i) the unconditional staggered DiD - column (1); ii) estimates under sample selections of municipalities - column (3); and iii) estimates under sample selections and spillover effects - column (4).

Figure 5 depicts a positive and statistically significant impact of wind power on employment at the exact moment of intervention and for the two periods prior to wind farm implementation. We investigate this result in-depth by specifically estimating the same equation for each sector of the economy, and in terms of worker educational levels and firm sizes, in Figures 6, 7, and 8. respectively. These charts allow us to observe that the effects of two periods prior to the intervention are driven by the construction, and commerce and services sectors, and are most prominent for high school workers and large-sized firms. 

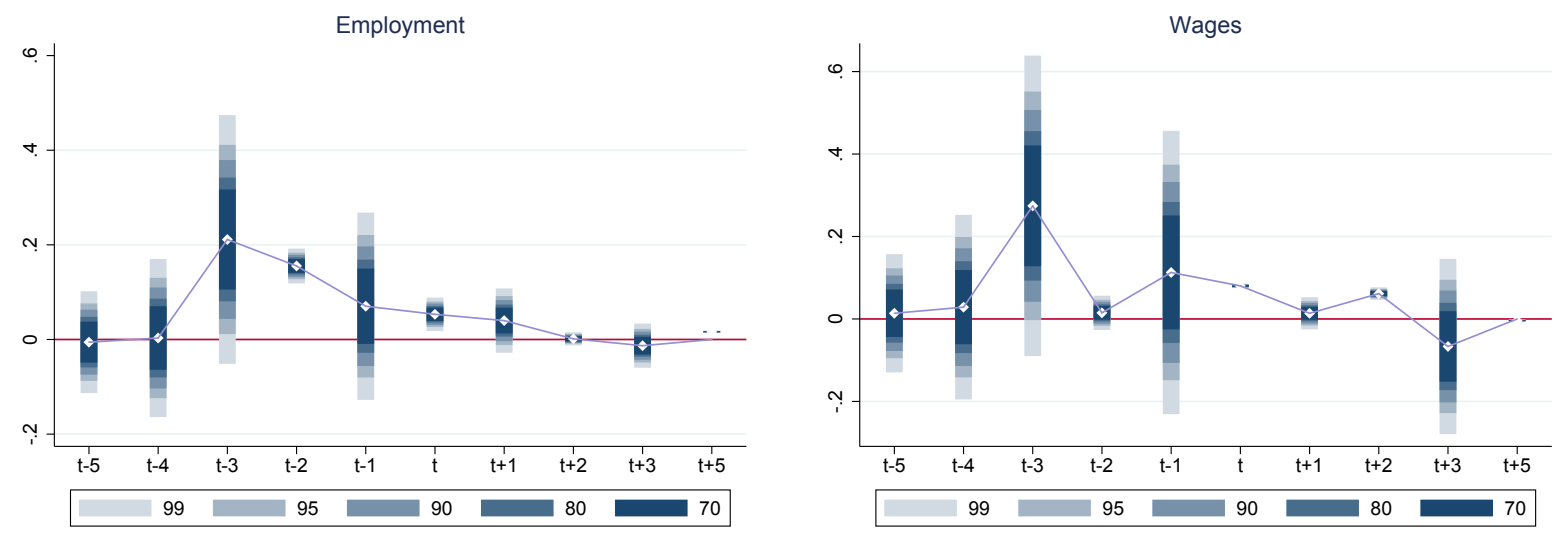

Figure 5: Event-study analysis

Note: Graphical result of the estimation of Equation (2) under the benchmark specification - with population weights, covariates, and fixed effects for States - which meets the common trend criteria.

It is important to note that the reliability of the causal interpretation of the estimated effects in an event study design depends on the non-existence of anticipatory effects of treatment. Such anticipatory effects are not expected to occur, since the incentives for the implementation of a wind farm project in a municipality, is mainly driven by a totally exogenous variable, namely the wind speed. Moreover, the submitted projects are evaluated based on certain technical guidelines, prior to being approved for consideration in an energy auction. Therefore, these anticipation of treatment effects could be related to the construction phase of wind farms, which lasts, on average, from eleven to eighteen months. Figures 6 to 8 evidence this fact, since we observe the prominence of this sector, in combination with the commerce and services, besides large-sized firms and workers with high-scholl, which could also be characteristics of firms and employees of this sectors.

Unfortunately, we do not have information regarding the exact moment of the start of the construction phase of wind farms but only the date in which the wind farms beggin to operate. Indeed, we simulate an event study analysis under the assumption that the intervention event would be the construction of wind farms, and we estimate the dynamic treatment effects by defining the beginning of the intervention as two years prior to the date in which each wind farm has started operatting. The results of this simulation are shown in Figure 9. We observe the dissipation of the anticipatory effects whether we consider a two-year period prior to the operational date as the intervention event, thereby evidencing the importance of accounting for this phase if the data is available.

The results for wage levels in Figure 5 reveal impacts mainly at the exact moment of the intervention and during the two post-intervention periods. The analysis of the heterogeneity of these post-intervention effects for wages is depicted in Appendices C.2, C.4, and C.6. We observe 

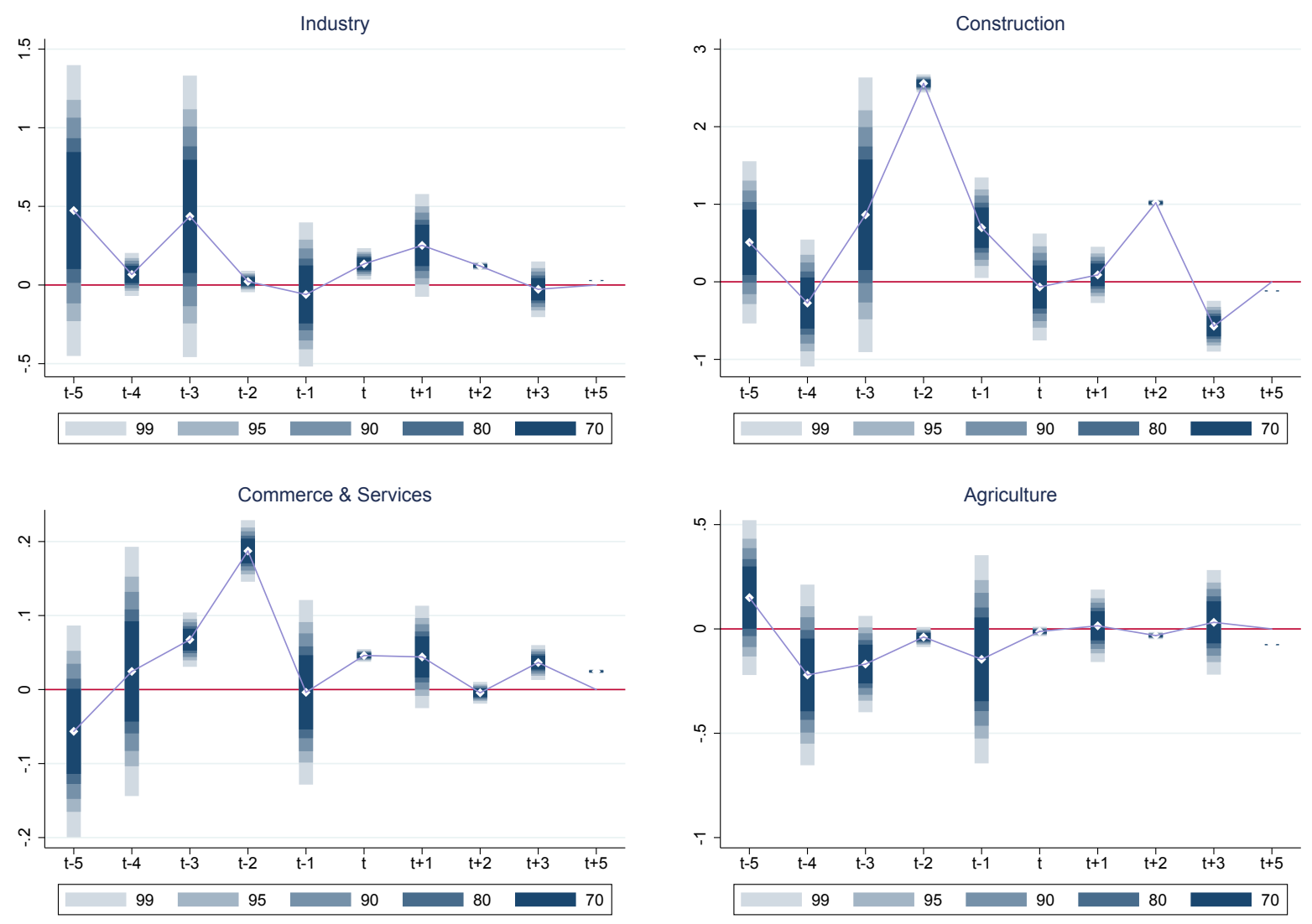

Figure 6: Event-study analysis: heterogeneity of the employment based on economic sectors

Note: Graphical result of the estimation of Equation (2) under the benchmark specification - with population weights, covariates, and fixed effects for States - which meets the common trend criteria.

that the two post-intervention impacts on wages are driven by the construction, commerce and services, and agriculture sectors, with the largest impact applying to workers with primary and secondary educational levels, and to medium-sized firms. The impacts in the two postintervention periods can be explained by the indirect effects of wind energy spreading throughout the local economy. Impacts are also expected for the agricultural sector, since the incomes of landowners increase due to land leasing. Moreover, the possibility of coexistence of agricultural and livestock activities and wind farms potentialize the income of farmers.

We observe in Appendices B.1 and B.2 the sensitivity of the results on the tested specifications. However, even though the magnitude of the contemporaneous coefficients ranged from $4.5 \%$ to $5.3 \%$, for employment, and from $8.0 \%$ to $9.3 \%$, for wages, all specifications reveal statistically significant effects for the exact time of wind farm implementation. In order to evaluate the reliability of the causal results, it is important to test the common trend assumption via i) a joint test of significance on leads (Test parallel trend 1), or ii) a time-trend significance test 

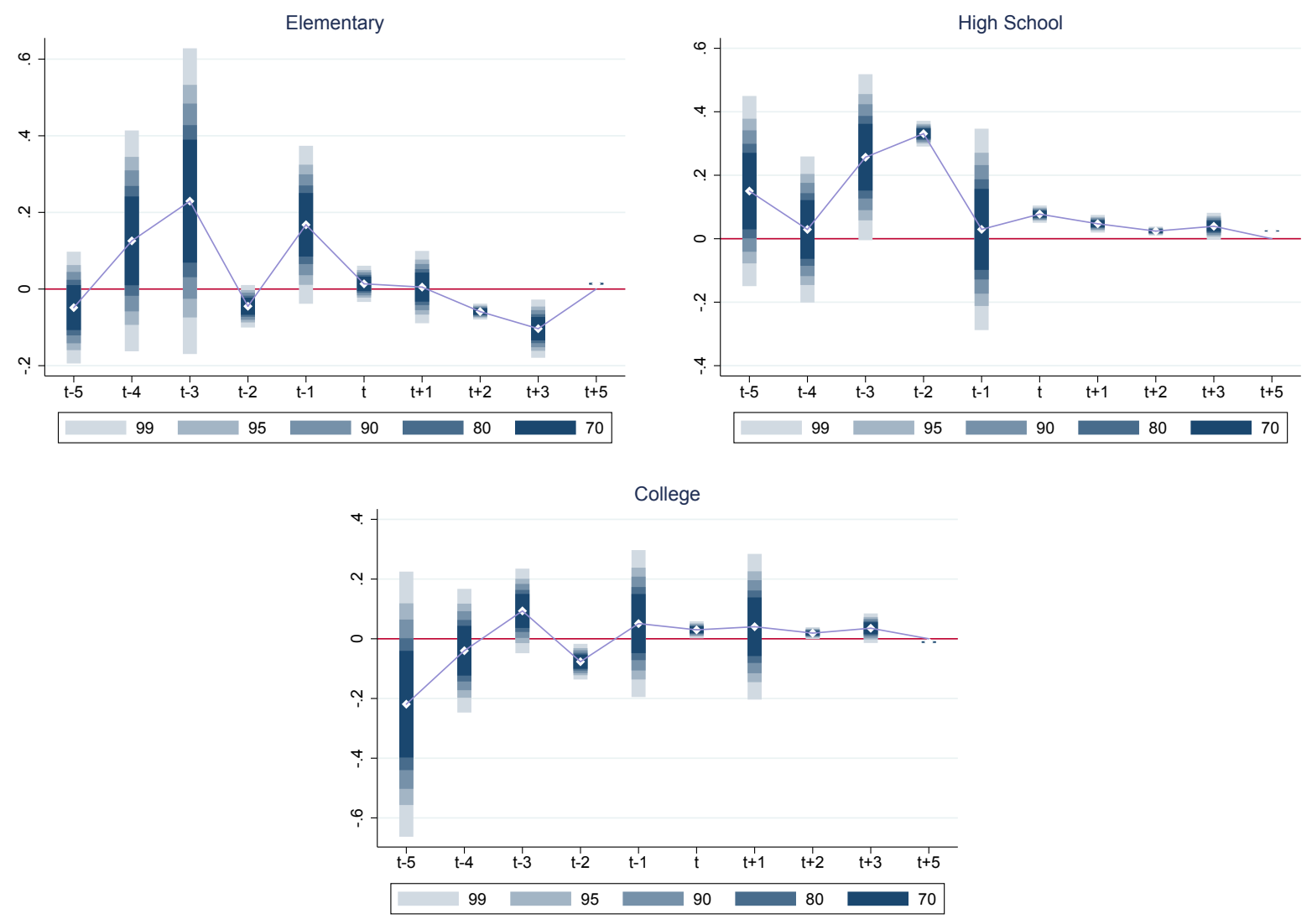

Figure 7: Event-study analysis: heterogeneity of the employment based on the schooling of workers

Note: Graphical result of the estimation of Equation (2) under the benchmark specification - with population weights, covariates, and fixed effects for States.

(Test parallel trend 2). These tests enable the verification of the non-violation of the common trend hypothesis for the concerned specification $(2)]_{7}^{7}$

Finally, it is worth highlighting that the contemporaneous coefficients derived in the event study analysis are not comparable to those derived and depicted in Section 4.1. The standard DiD estimator, under a random adoption date assumption, could be interpreted as the weighted average of several types of causal effects, for example, the impact of changing from never adopting to adopting in the first period, or changing from never adopting to adopting later [5].

\footnotetext{
${ }^{7}$ For which the figures in Section 4.2 are generated.
} 

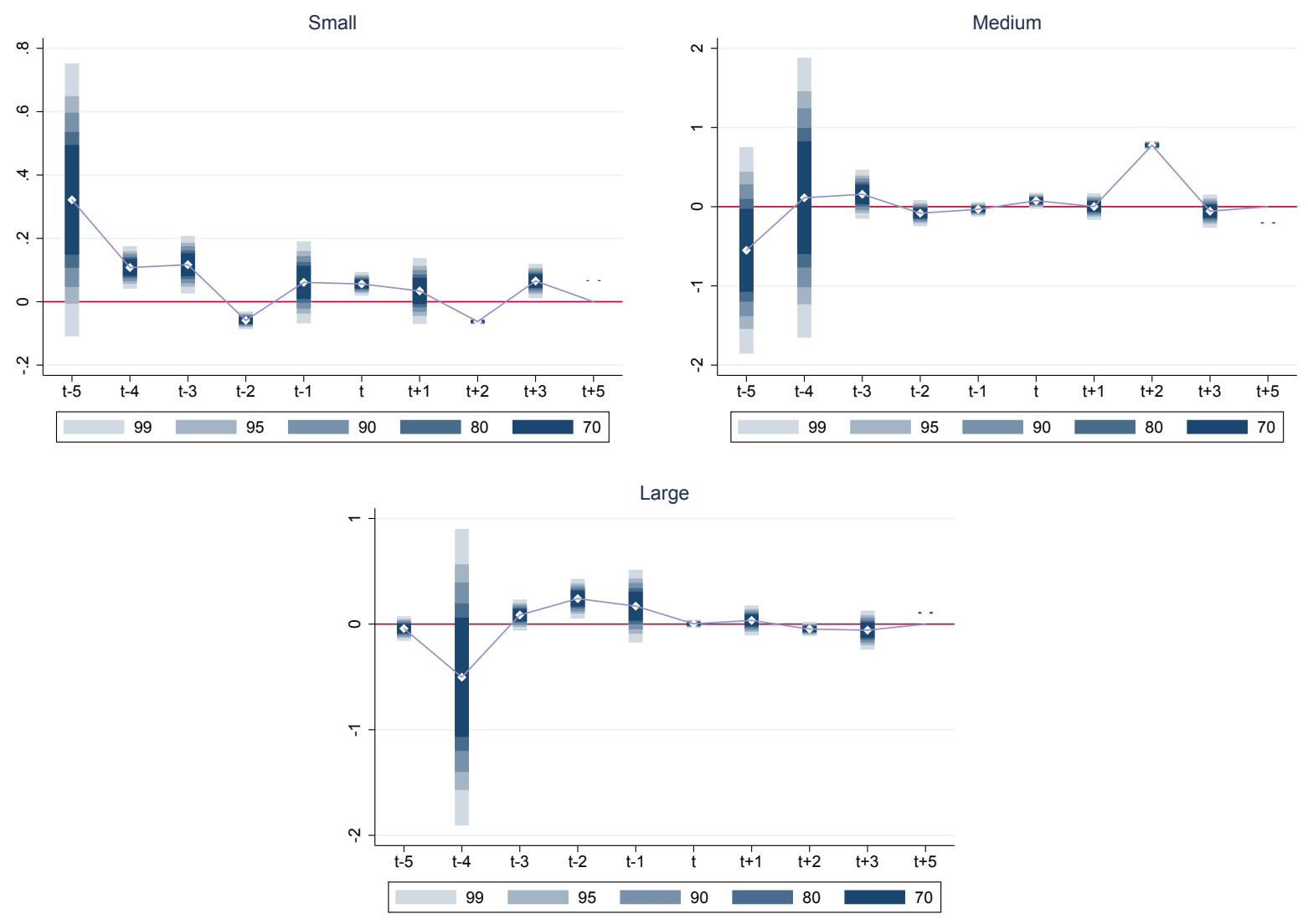

Figure 8: Event-study analysis: heterogeneity of the employment based on firm sizes

Note: Graphical result of the estimation of Equation (2) under the benchmark specification - with population weights, covariates, and fixed effects for States - which meets the common trend criteria.
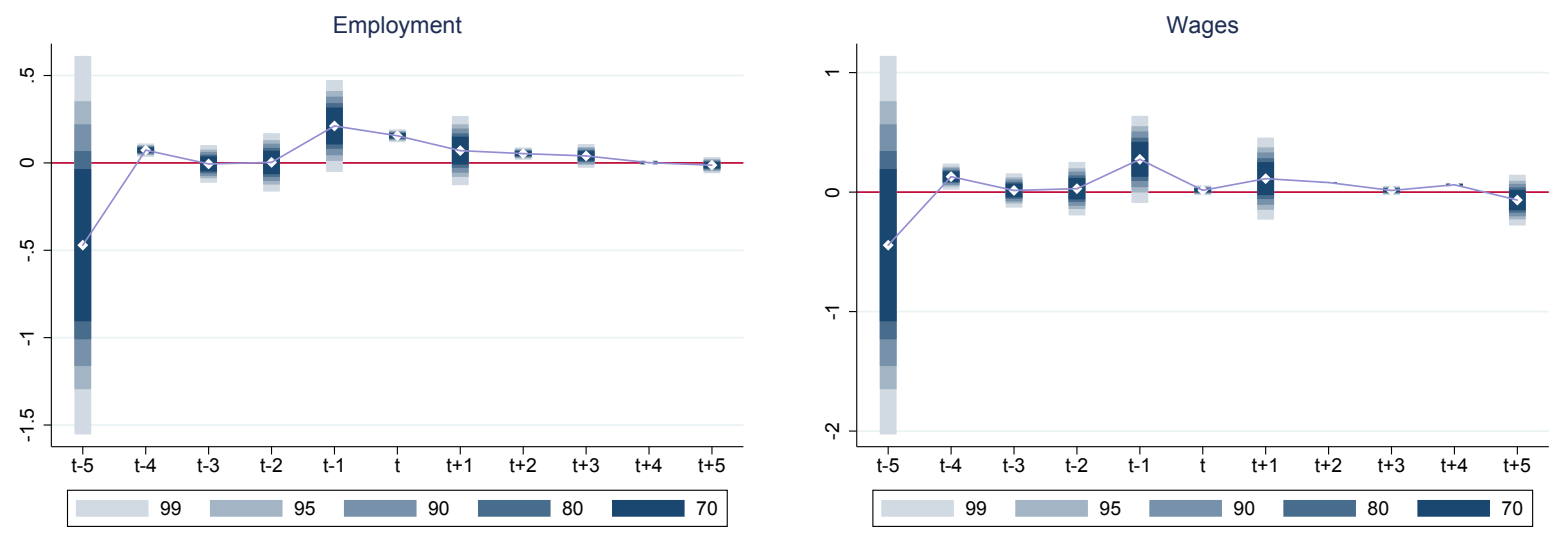

Figure 9: Event-study analysis: simulation for two years of construction phase

Note: Graphical result of the estimation of Equation (2) under the benchmark specification - with population weights, covariates, and fixed effects for States. 


\section{Concluding remarks and discussion}

Wind power is an important source of renewable energy. In addition to the environmental impacts, wind energy is relevant in the context of contributing to local development. Despite the existence of studies whose focal points are the socioeconomic impacts of wind power, their methodological approaches do not allow for isolating the effects of wind farm implementation. The innovative aspect of our study is accounting for the fact that wind farms are installed at a particular point in time, such that municipalities henceforth, remain exposed to this treatment at all times afterwards. We thus, explore the staggered nature of the sequential process of wind farms implementation in Brazil, from 2004 to 2016.

Our results suggest that wind energy not only increases employment in the industrial, agricultural and construction sectors, but also increases wage levels across all sectors in the economy, including commerce and services. Indeed, it is possible to observe positive and statistically significant effects of wind farm implementation on the employment and wages of workers with elementary and high school educational levels, and workers employed in small and medium-sized firms.

In the second application of the staggered DiD, in which we consider the dynamic treatment effects of wind farm implementation, we find positive and statistically significant impacts of wind power on employment at the exact moment of the intervention and at two periods prior to wind farm implementation. However, we verify through heterogeneity analysis and simulations, that this anticipatory effect is related to the construction phase of wind farms, whose start date is unavailable in our database. Regarding wage levels, we find contemporaneous impacts and effects for the two post-intervention periods, which are driven by the sectors of construction, commerce and services, and agriculture. The impact for the two post-intervention periods can be explained by the indirect effects of wind energy spreading throughout the local economy. Impacts are also expected for the agricultural sector, since the incomes of landowners increase due to land leasing. The contemporaneous effect of wind power, that is, the effects that occurs in the exact moment of the wind farm implementation, is $5.3 \%$ on employment and $8.0 \%$ on wages.

The findings of this study suggest that the expansion of wind power may generate relevant social impacts through favorable labor market outcomes, mainly for the less-skilled workers, thereby contributing to local development geared towards increasing social welfare and reducing social inequalities in developing countries. For Brazil, we can expect that the expansion of the wind turbines industry, the strengthening of the energy auctions, as well as, the economic growth provide conditions that are conducive for the development of the wind power in the country, since favorable wind speed conditions constitute a natural and exogenous factor that can ensure sufficient wind power generation. 


\section{References}

[1] Abadie, A. Semiparametric difference-in-differences estimators. The Review of Economic Studies 72, 1 (2005), 1-19.

[2] Abraham, S., And Sun, L. Estimating dynamic treatment effects in event studies with heterogeneous treatment effects. Available at SSRN 3158747 (2018).

[3] ANEEL. Micro e minigeração distribuída. Tech. rep., Cadernos Temáticos. Sistema de Compensação de Energia Elétrica. Centro de Documentação-Cedoc, Brasília, Brasil, 2014.

[4] Athey, S., And Imbens, G. W. Identification and inference in nonlinear difference-indifferences models. Econometrica 74, 2 (2006), 431-497.

[5] Athey, S., and Imbens, G. W. Design-based analysis in difference-in-differences settings with staggered adoption. National Bureau of Economic Research, NBER working paper $n$. w24963 (2018).

[6] Bergmann, A., Hanley, N., And Wright, R. Valuing the attributes of renewable energy investments. Energy policy 34, 9 (2006), 1004-1014.

[7] Bertrand, M., Duflo, E., And Mullainathan, S. How much should we trust differences-in-differences estimates? The Quarterly journal of economics 119, 1 (2004), 249-275.

[8] Blanco, M. I., And Rodrigues, G. Direct employment in the wind energy sector: An eu study. Energy policy 37, 8 (2009), 2847-2857.

[9] Borusyak, K., And Jaravel, X. Revisiting event study designs. Available at SSRN 2826228 (2017).

[10] Botosaru, I., And Gutierrez, F. H. Difference-in-differences when the treatment status is observed in only one period. Journal of Applied Econometrics 33, 1 (2018), 73-90.

[11] Callaway, B., Li, T., And OKa, T. Quantile treatment effects in difference in differences models under dependence restrictions and with only two time periods. Journal of Econometrics 206, 2 (2018), 395-413.

[12] Callaway, B., and Sant'Anna, P. H. Difference-in-differences with multiple time periods and an application on the minimum wage and employment. Forthcoming: arXiv preprint arXiv:1803.09015 (2018).

[13] Costa, R. A., Casotti, B. P., and Azevedo, R. L. S. Um panorama da indústria de bens de capital relacionados à energia eólica. Tech. rep., Banco Nacional de Desenvolvimento Econômico e Social, 2009. 
[14] De Chaisemartin, C., And D'Haultfoeullle, X. Fuzzy differences-in-differences. The Review of Economic Studies 85, 2 (2017), 999-1028.

[15] de Chaisemartin, C., D’Haultfoullle, X., et Al. Two-way fixed effects estimators with heterogeneous treatment effects. National Bureau of Economic Research, NBER working paper n. w25904 (2019).

[16] Del Río, P., And Burguillo, M. Assessing the impact of renewable energy deployment on local sustainability: Towards a theoretical framework. Renewable and sustainable energy reviews 12, 5 (2008), 1325-1344.

[17] Edenhofer, O., Pichs Madruga, R., Sokona, Y., Seyboth, K., and Matschoss, P. Summary for policymakers: Ipcc special report on renewable energy sources and climate change mitigation. Tech. rep., Working Group III of the Intergovernmental Panel on Climate Change, Cambridge University Press, Cambridge, UK, 2011.

[18] EPE. O compromisso do brasil no combate às mudanças climáticas: produção e uso de energia. Tech. rep., Empresa de Pesquisa Energética, MME, Rio de Janeiro, Brasil, 2016.

[19] Goodman-Bacon, A. Difference-in-differences with variation in treatment timing. National Bureau of Economic Research, NBER working paper n. w25018 (2018).

[20] GWEC. Global wind statistics 2011 report. Tech. rep., Global Wind Energy Council, Brussels, Belgium, 2011.

[21] GWEC. Global wind report 2018. Tech. rep., Global Wind Energy Council, Brussels, Belgium, 2018.

[22] Heckman, J., Ichimura, H., Smith, J., And Todd, P. Characterizing selection bias using experimental data. Econometrica 66, 5 (1998), 1017-1098.

[23] Heckman, J. J., Ichimura, H., And Todd, P. E. Matching as an econometric evaluation estimator: Evidence from evaluating a job training programme. The review of economic studies 64, 4 (1997), 605-654.

[24] IRENA. Renewable energy and jobs annual review 2018. Tech. rep., International Renewable Energy Agency, 2018.

[25] Jacobson, L. S., Lalonde, R. J., and Sullivan, D. G. Earnings losses of displaced workers. The American economic review (1993), 685-709.

[26] Martini, R. A., Jordão, M. D. F., And Grimaldi, D. D. S. Avaliação de efeitos locais da construção de usinas eólicas nos municípios brasileiros: uma abordagem pr controle sintético. Proceedings of the 46th Brazilian Economics Meeting (2018). 
[27] Moreno, B., And Lopez, A. J. The effect of renewable energy on employment. the case of asturias (spain). Renewable and Sustainable Energy Reviews 12, 3 (2008), 732-751.

[28] Rintzel, L. T., Alves, T. W., and Massuquetti, A. Análise dos impactos econômicos decorrentes da instalação dos parques eólicos nos municípios brasileiros. Proceedings of the 20th Economics Meeting of the Brazilian South Region (2017).

[29] Simas, M., And Pacca, S. Assessing employment in renewable energy technologies: A case study for wind power in brazil. Renewable and Sustainable Energy Reviews 31 (2014), 83-90.

[30] Wei, M., Patadia, S., and Kammen, D. M. Putting renewables and energy efficiency to work: How many jobs can the clean energy industry generate in the us? Energy policy 38, 2 (2010), 919-931. 


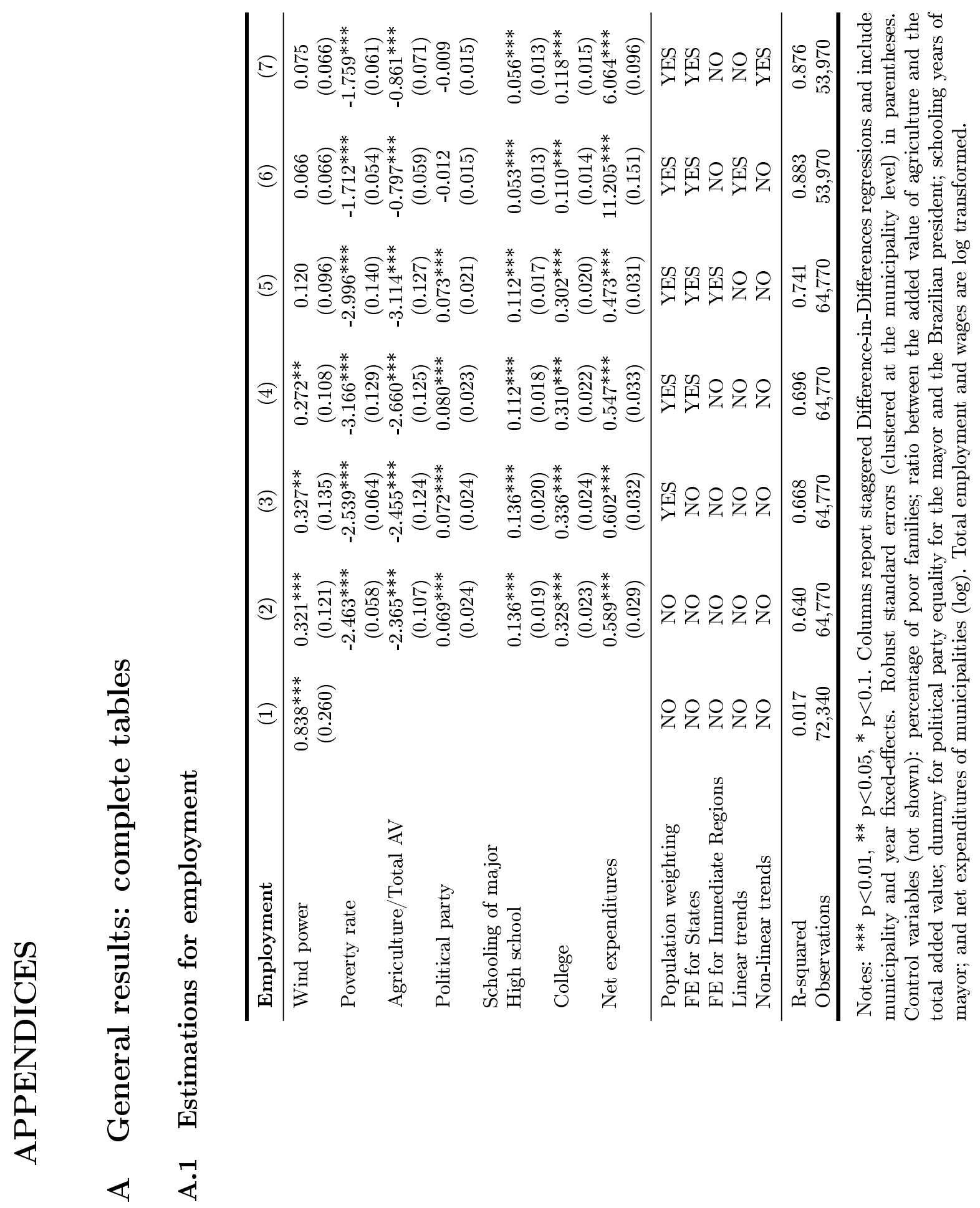




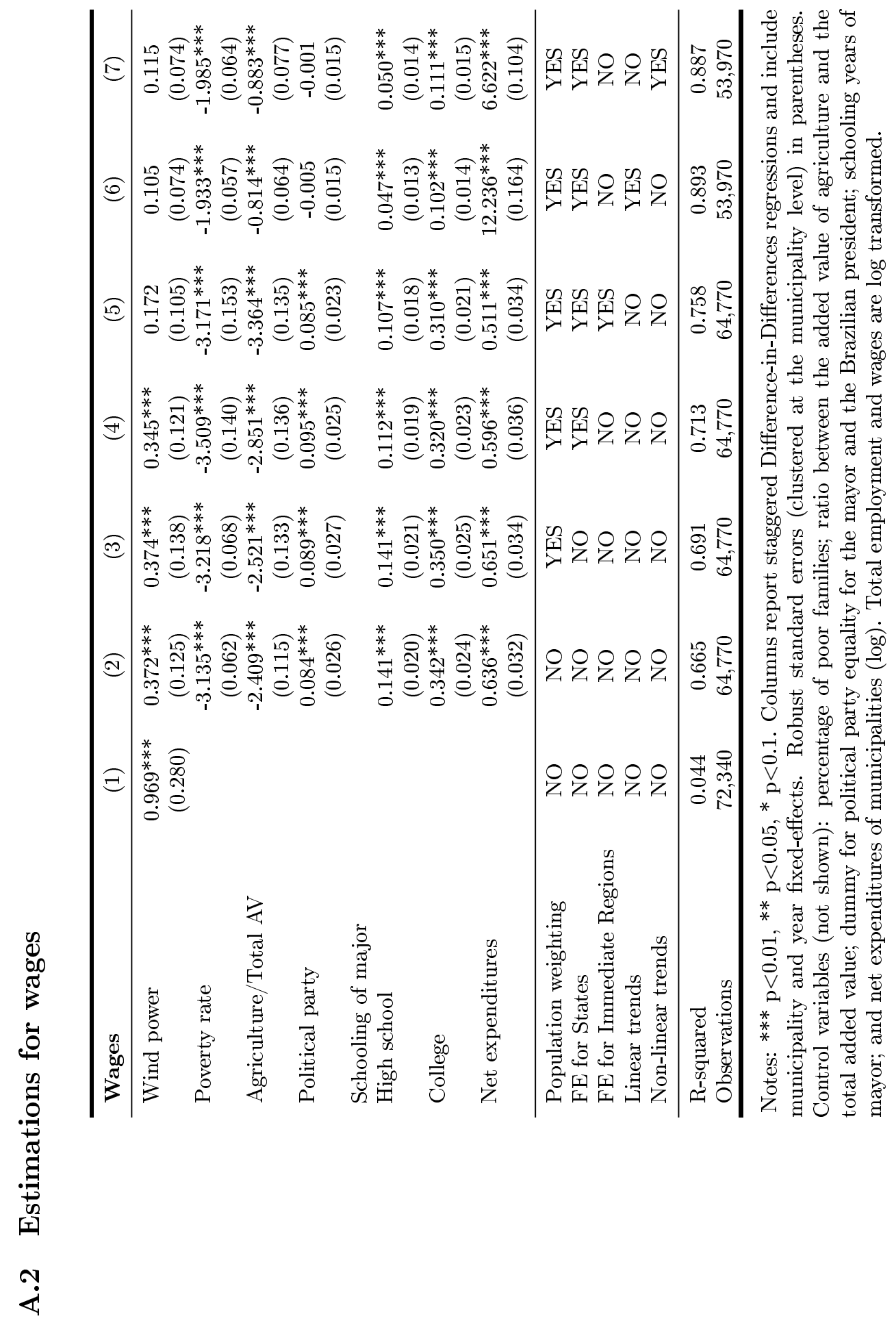




\section{B Event-study: general results}

\section{B.1 Estimations for employment}

\begin{tabular}{|c|c|c|c|c|}
\hline Employment & (1) & $(2)$ & (3) & (4) \\
\hline Wind Power - Year -5 & $\begin{array}{c}0.014 \\
(0.039)\end{array}$ & $\begin{array}{l}-0.006 \\
(0.042)\end{array}$ & $\begin{array}{l}-0.007 \\
(0.042)\end{array}$ & $\begin{array}{c}0.041^{* * *} \\
(0.013)\end{array}$ \\
\hline Wind Power - Year -4 & $\begin{array}{c}0.061 \\
(0.044)\end{array}$ & $\begin{array}{c}0.003 \\
(0.065)\end{array}$ & $\begin{array}{l}-0.007 \\
(0.081)\end{array}$ & $\begin{array}{c}0.084^{* *} \\
(0.034)\end{array}$ \\
\hline Wind Power - Year -3 & $\begin{array}{c}0.161^{* * *} \\
(0.055)\end{array}$ & $\begin{array}{c}0.211^{* *} \\
(0.102)\end{array}$ & $\begin{array}{c}0.239^{* *} \\
(0.117)\end{array}$ & $\begin{array}{c}0.060^{* *} \\
(0.025)\end{array}$ \\
\hline Wind Power - Year -2 & $\begin{array}{c}0.000 \\
(0.034)\end{array}$ & $\begin{array}{c}0.155^{* * *} \\
(0.014)\end{array}$ & & $\begin{array}{l}-0.333 \\
(0.314)\end{array}$ \\
\hline Wind Power - Year -1 & $\begin{array}{l}0.076^{*} \\
(0.04)\end{array}$ & $\begin{array}{c}0.070 \\
(0.077)\end{array}$ & $\begin{array}{c}-0.071^{* * *} \\
(0.002)\end{array}$ & $\begin{array}{l}-0.005 \\
(0.023)\end{array}$ \\
\hline Wind Power - Year 0 & $\begin{array}{c}0.017 \\
(0.034)\end{array}$ & $\begin{array}{c}0.053^{* * *} \\
(0.014)\end{array}$ & $\begin{array}{c}0.053^{* * *} \\
(0.014)\end{array}$ & $\begin{array}{c}0.045^{* * *} \\
(0.013)\end{array}$ \\
\hline Wind Power - Year +1 & $\begin{array}{c}0.105^{* * *} \\
(0.038)\end{array}$ & $\begin{array}{c}0.039 \\
(0.026)\end{array}$ & $\begin{array}{c}0.038 \\
(0.027)\end{array}$ & $\begin{array}{c}0.053^{* * *} \\
(0.016)\end{array}$ \\
\hline Wind Power - Year +2 & $\begin{array}{l}0.092^{*} \\
(0.054)\end{array}$ & $\begin{array}{c}0.001 \\
(0.005)\end{array}$ & $\begin{array}{l}-0.001 \\
(0.006)\end{array}$ & $\begin{array}{l}-0.005 \\
(0.031)\end{array}$ \\
\hline Wind Power - Year +3 & $\begin{array}{c}0.016 \\
(0.035)\end{array}$ & $\begin{array}{l}-0.013 \\
(0.018)\end{array}$ & $\begin{array}{l}-0.014 \\
(0.025)\end{array}$ & $\begin{array}{l}0.043^{*} \\
(0.027)\end{array}$ \\
\hline Wind Power - Year +4 & $\begin{array}{c}0.049 \\
(0.018)\end{array}$ & & & $\begin{array}{l}-0.024 \\
(0.047)\end{array}$ \\
\hline Wind Power - Year +5 & $\begin{array}{l}0.125^{*} \\
(0.065)\end{array}$ & $\begin{array}{c}0.016^{* * *} \\
(0.001) \\
\end{array}$ & $\begin{array}{c}0.016^{* * *} \\
(0.001) \\
\end{array}$ & $\begin{array}{c}0.022 \\
(0.016) \\
\end{array}$ \\
\hline Test parallel trend 1 & NO & NO & NO & NO \\
\hline Test parallel trend 2 & $\mathrm{NO}$ & YES & $\mathrm{NO}$ & NO \\
\hline Controls & $\mathrm{NO}$ & YES & YES & YES \\
\hline Population weighting & NO & YES & YES & YES \\
\hline FE for States & NO & YES & YES & YES \\
\hline Sample selections & NO & $\mathrm{NO}$ & YES & YES \\
\hline Spillover & $\mathrm{NO}$ & $\mathrm{NO}$ & $\mathrm{NO}$ & YES \\
\hline Observações & 27,739 & 8,925 & 6,806 & 6,806 \\
\hline
\end{tabular}

Notes: $* * * \mathrm{p}<0.01,{ }^{* *} \mathrm{p}<0.05,{ }^{*} \mathrm{p}<0.1$. Columns report staggered Differencein-Differences regressions and include municipality and year fixed-effects. Robust standard errors (clustered at the municipality level) in parentheses. Column (1): unconditional staggered DiD; column (2): estimates under the benchmark specification; column (3): estimates under sample selections of municipalities - exclusion of capitals and MAs; column (4): estimates under sample selections and spillover effects $-100 \mathrm{~km}$ buffer. Control variables (not shown): percentage of poor families; ratio between the added value of agriculture and the total added value; dummy for political party equality for the mayor and the Brazilian president; schooling years of mayor; and net expenditures of municipalities (log). 


\section{B.2 Estimations for wages}

\begin{tabular}{|c|c|c|c|c|}
\hline Wages & (1) & (2) & $(3)$ & (4) \\
\hline Wind Power - Year -5 & $\begin{array}{c}0.126^{* * *} \\
(0.047)\end{array}$ & $\begin{array}{c}0.014 \\
(0.056)\end{array}$ & $\begin{array}{c}0.012 \\
(0.056)\end{array}$ & $\begin{array}{c}0.083^{* * *} \\
(0.024)\end{array}$ \\
\hline Wind Power - Year - 4 & $\begin{array}{c}0.118^{* *} \\
(0.05)\end{array}$ & $\begin{array}{c}0.028 \\
(0.087)\end{array}$ & $\begin{array}{c}0.007 \\
(0.108)\end{array}$ & $\begin{array}{c}0.184^{* * *} \\
(0.04)\end{array}$ \\
\hline Wind Power - Year -3 & $\begin{array}{c}0.242^{* * *} \\
(0.073)\end{array}$ & $\begin{array}{l}0.274^{*} \\
(0.141)\end{array}$ & $\begin{array}{l}0.304^{*} \\
(0.164)\end{array}$ & $\begin{array}{r}0.150^{* * *} \\
(0.052)\end{array}$ \\
\hline Wind Power - Year -2 & $\begin{array}{c}0.053 \\
(0.041)\end{array}$ & $\begin{array}{c}0.014 \\
(0.016)\end{array}$ & & $\begin{array}{l}-0.485 \\
(0.392)\end{array}$ \\
\hline Wind Power - Year -1 & $\begin{array}{c}0.140^{* * *} \\
(0.03)\end{array}$ & $\begin{array}{c}0.112 \\
(0.133)\end{array}$ & $\begin{array}{c}-0.055^{* * *} \\
(0.002)\end{array}$ & $\begin{array}{c}0.038 \\
(0.025)\end{array}$ \\
\hline Wind Power - Year 0 & $\begin{array}{c}0.093^{* * *} \\
(0.03)\end{array}$ & $\begin{array}{c}0.080^{* * *} \\
(0.002)\end{array}$ & $\begin{array}{c}0.080 * * * \\
(0.002)\end{array}$ & $\begin{array}{c}0.085^{* * *} \\
(0.01)\end{array}$ \\
\hline Wind Power - Year +1 & $\begin{array}{c}0.121^{* * *} \\
(0.027)\end{array}$ & $\begin{array}{c}0.013 \\
(0.015)\end{array}$ & $\begin{array}{c}0.011 \\
(0.015)\end{array}$ & $\begin{array}{r}0.110^{* * *} \\
(0.018)\end{array}$ \\
\hline Wind Power - Year +2 & $\begin{array}{c}0.088 \\
(0.059)\end{array}$ & $\begin{array}{c}0.061^{* * *} \\
(0.006)\end{array}$ & $\begin{array}{c}0.057^{* * *} \\
(0.007)\end{array}$ & $\begin{array}{c}0.028 \\
(0.041)\end{array}$ \\
\hline Wind Power - Year +3 & $\begin{array}{l}0.024 \\
(0.05)\end{array}$ & $\begin{array}{l}-0.066 \\
(0.083)\end{array}$ & $\begin{array}{c}0.022 \\
(0.018)\end{array}$ & $\begin{array}{c}0.108^{* * *} \\
(0.038)\end{array}$ \\
\hline Wind Power - Year +4 & $\begin{array}{c}0.137 \\
(0.031)\end{array}$ & & & $\begin{array}{l}-0.021 \\
(0.055)\end{array}$ \\
\hline Wind Power - Year +5 & $\begin{array}{c}0.225^{* * *} \\
(0.081)\end{array}$ & $\begin{array}{c}-0.004^{* * *} \\
(0.001)\end{array}$ & $\begin{array}{c}-0.004^{* * *} \\
(0.001)\end{array}$ & $\begin{array}{c}0.066^{* * *} \\
(0.021)\end{array}$ \\
\hline Test parallel trend 1 & NO & YES & NO & $\mathrm{NO}$ \\
\hline Test parallel trend 2 & YES & YES & NO & NO \\
\hline Controls & NO & YES & YES & YES \\
\hline Population weighting & $\mathrm{NO}$ & YES & YES & YES \\
\hline FE for States & NO & YES & YES & YES \\
\hline Sample selections & $\mathrm{NO}$ & $\mathrm{NO}$ & YES & YES \\
\hline Spillover & NO & NO & NO & YES \\
\hline Observações & 27,739 & 8,925 & 6,806 & 6,806 \\
\hline
\end{tabular}

Notes: $* * * \mathrm{p}<0.01,{ }^{* *} \mathrm{p}<0.05,^{*} \mathrm{p}<0.1$. Columns report staggered Differencein-Differences regressions and include municipality and year fixed-effects. Robust standard errors (clustered at the municipality level) in parentheses. Column (1): unconditional staggered DiD; column (2): estimates under the benchmark specification; column (3): estimates under sample selections of municipalities - exclusion of capitals and MAs; column (4): estimates under sample selections and spillover effects $100 \mathrm{~km}$ buffer. Control variables (not shown): percentage of poor families; ratio between the added value of agriculture and the total added value; dummy for political party equality for the mayor and the Brazilian president; schooling years of mayor; and net expenditures of municipalities (log). 


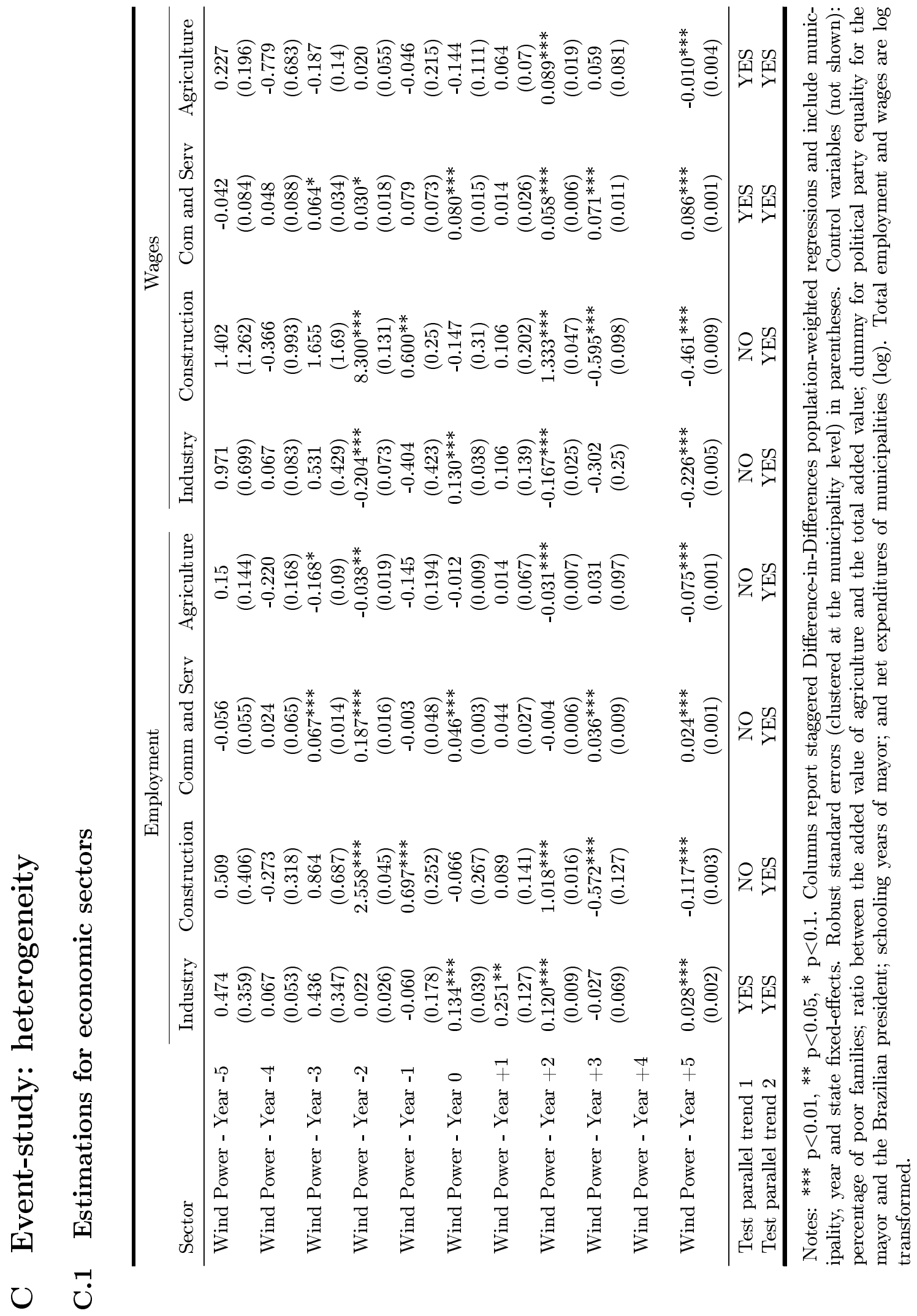




\section{C.2 Event-study analysis: heterogeneity of the wages in economic sectors}
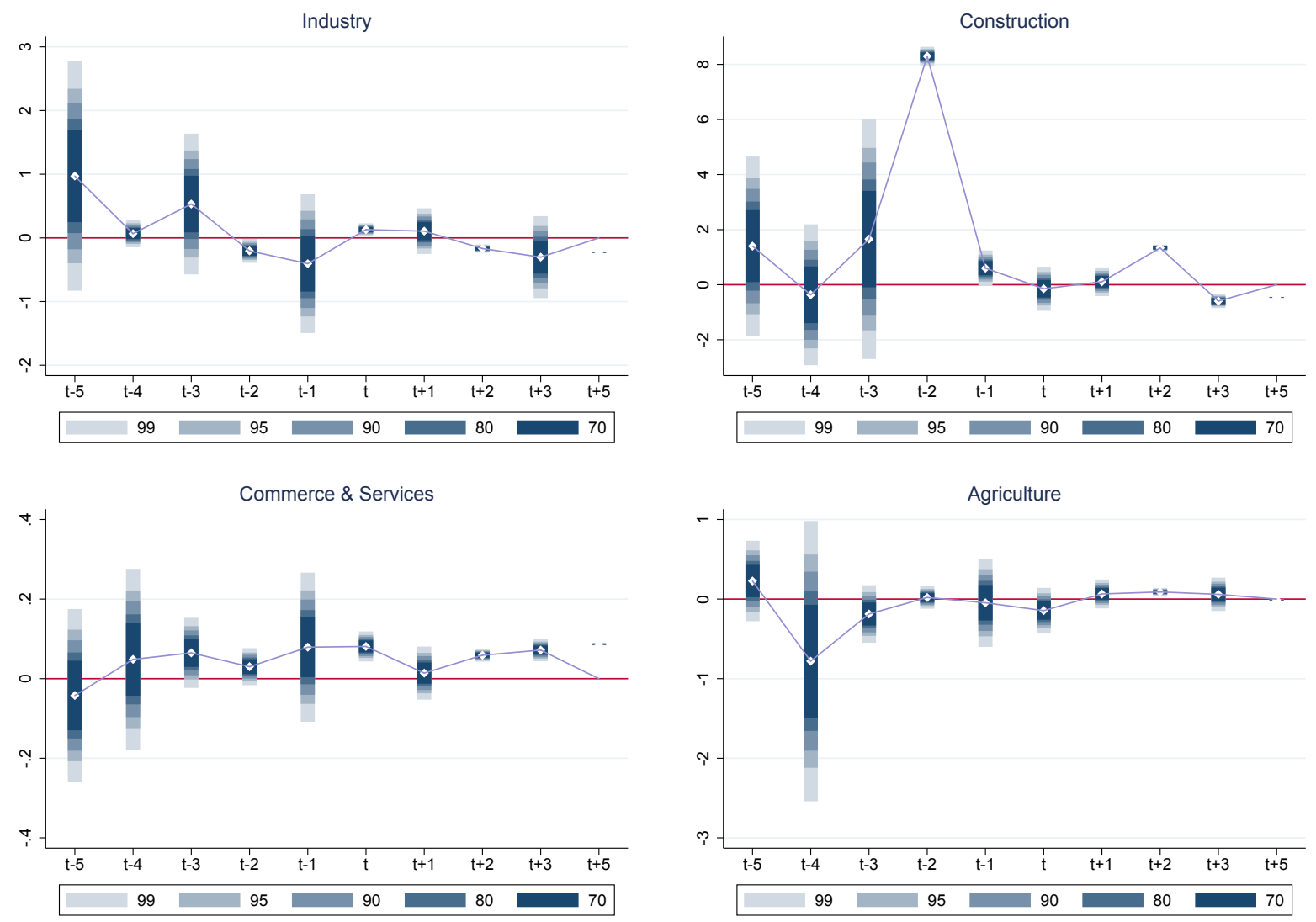

Note: Graphical result of the estimation of Equation (2) under the benchmark specification - with population weights, covariates, and fixed effects for States. 


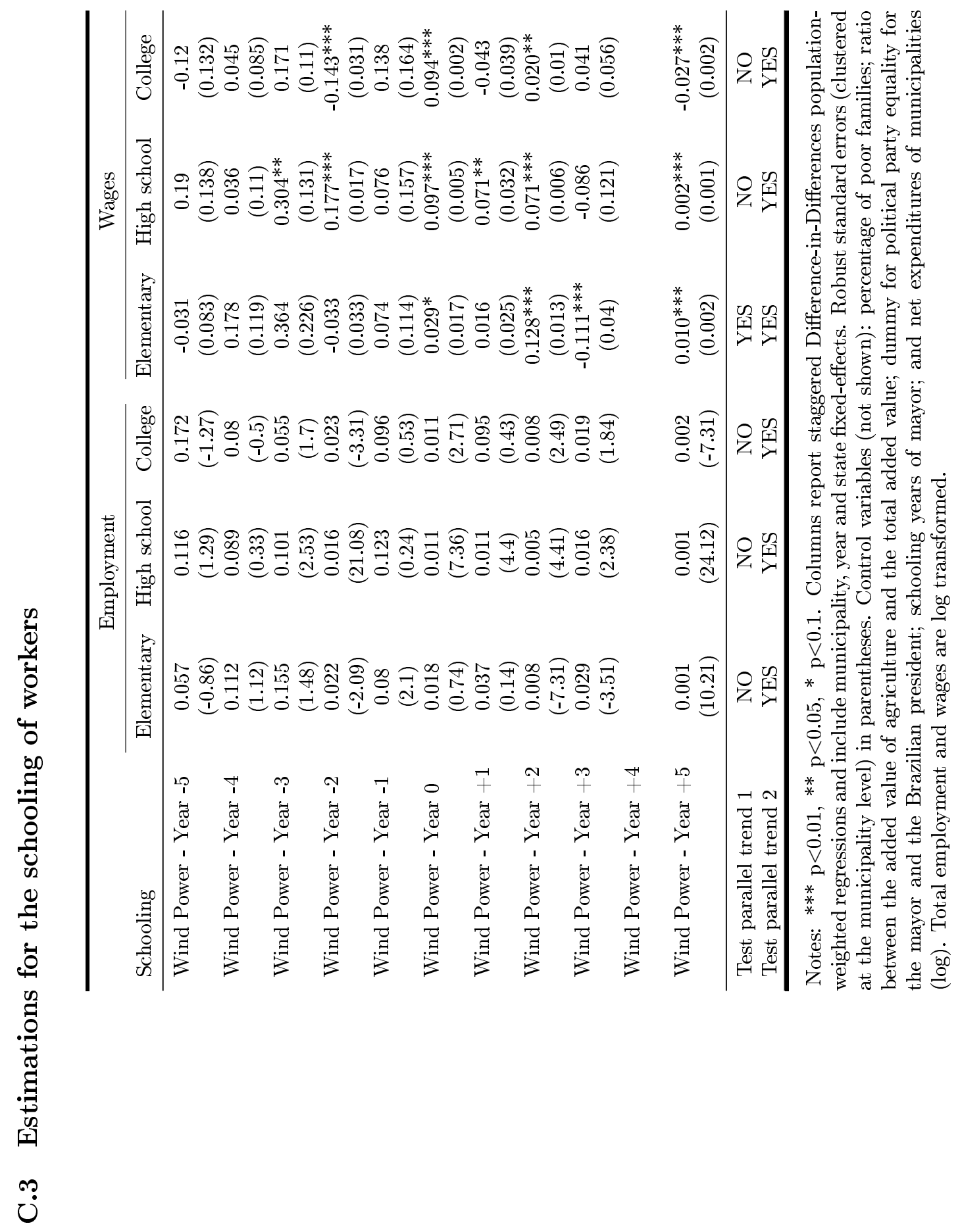




\section{C.4 Event-study analysis: heterogeneity of the wages in the schooling of workers}
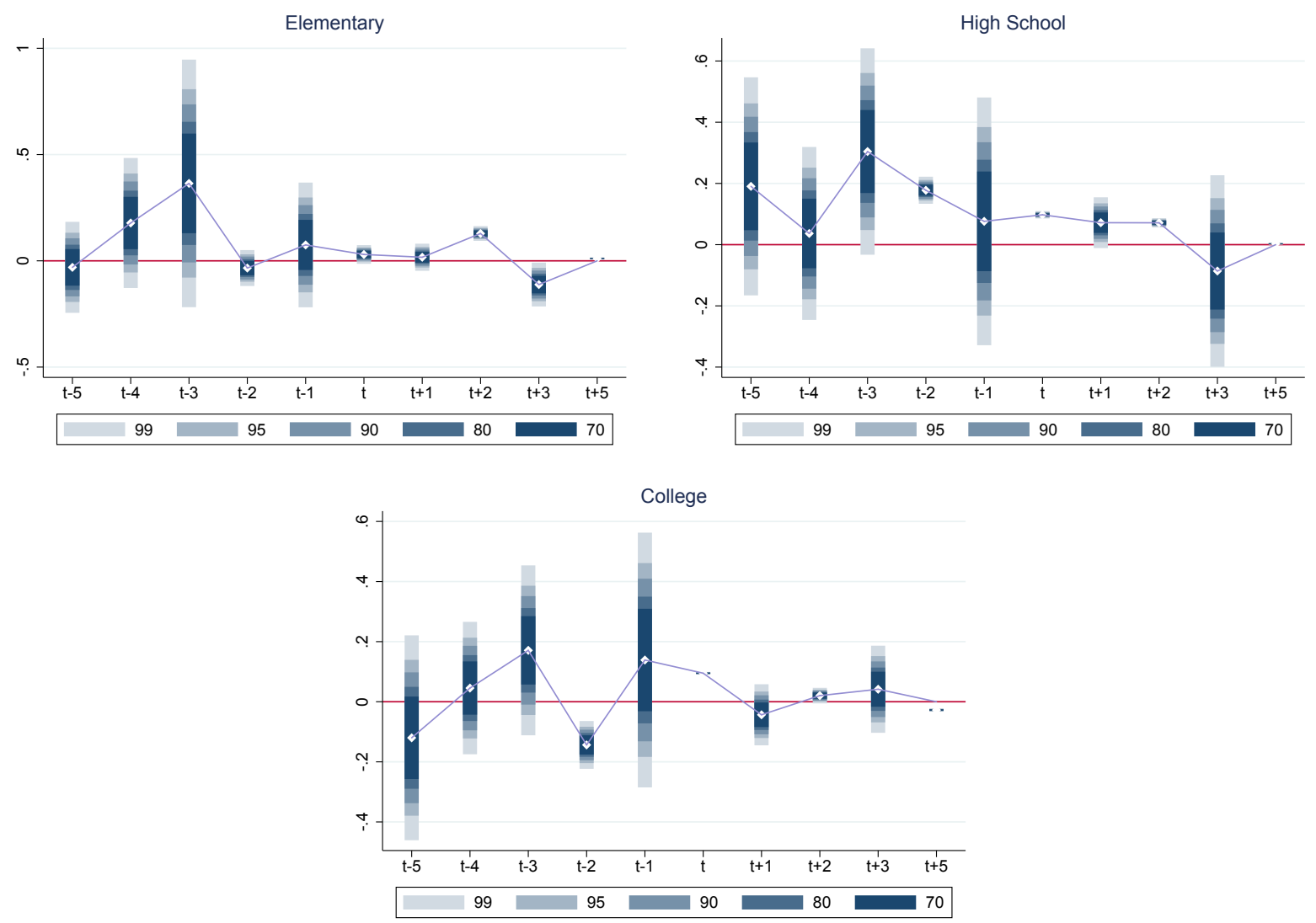

Note: Graphical result of the estimation of Equation (2) under the benchmark specification - with population weights, covariates, and fixed effects for States. 


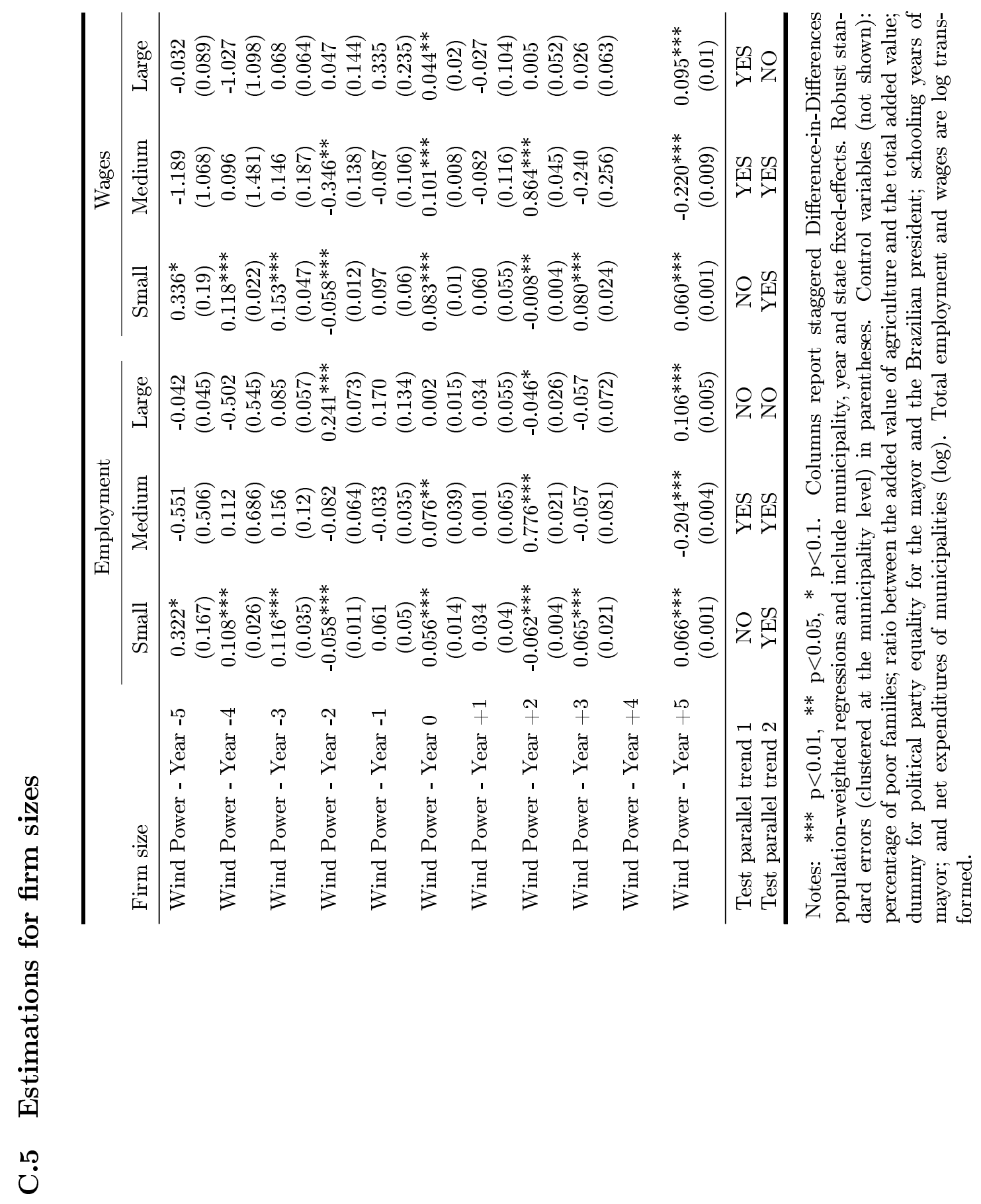




\section{C.6 Event-study analysis: heterogeneity of the wages in firm sizes}
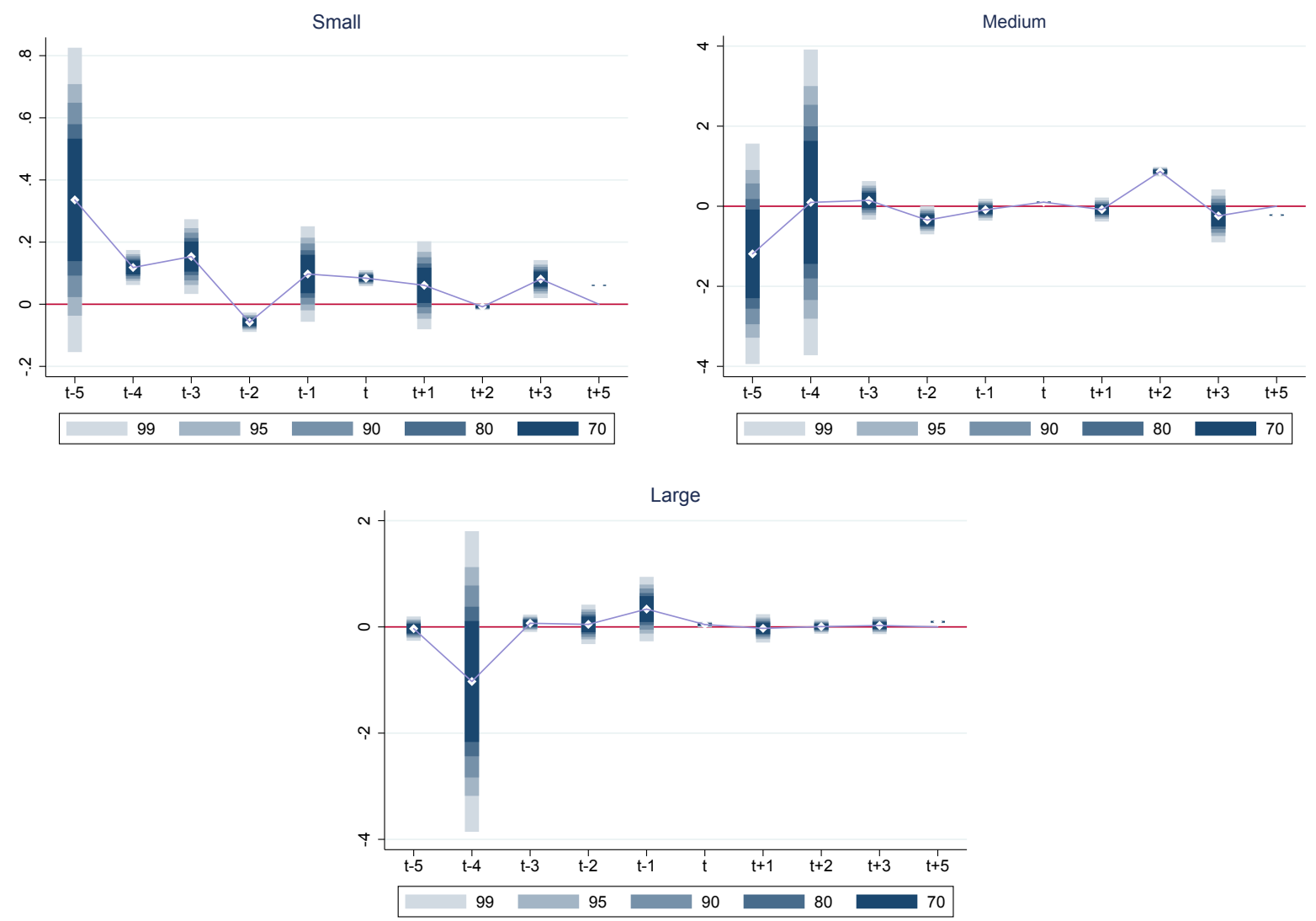

Note: Graphical result of the estimation of Equation (2) under the benchmark specification - with population weights, covariates, and fixed effects for States. 